\title{
Effects of Cobalt on the nucleation and grain refinement of $\mathrm{Sn-3Ag-0.5Cu}$ solders
}

\author{
Z.L. Ma*, S.A. Belyakov, C.M. Gourlay \\ Department of Materials, Imperial College, London. SW7 2AZ. UK \\ *z.ma13@imperial.ac.uk; +4407466266568
}

Keywords: intermetallics; EBSD; orientation relationship; Pb-free soldering; solidification

\begin{abstract}
We show that cobalt-microalloying causes significant grain refinement in large samples $(60 \mathrm{~g})$ of $\mathrm{Sn}-3 \mathrm{Ag}-0.5 \mathrm{Cu}$ solder. Nucleation occurs on the (100) facet of $\alpha \mathrm{CoSn}_{3}$ crystals with a reproducible orientation relationship of $(100)_{S n} \|(100)_{\operatorname{CoSn} 3}$ with $[001]_{S n} \|[001]_{\operatorname{CoSn} 3}$, which has a planar lattice mismatch of $\sim 4 \%$. In $550 \mu \mathrm{m}$ solder joints on $\mathrm{Cu}$ substrates, $\mathrm{Co}$ microalloying alters the $\beta \mathrm{Sn}$ nucleation location to an $\alpha \mathrm{CoSn}_{3}$ particle in the bulk liquid and increases the number of $\beta \mathrm{Sn}$ nucleation events when the cooling rate is higher than $\sim 5 \mathrm{~K} / \mathrm{s}$. However, Co-microalloying caused only weak grain refinement in sample volumes relevant to solder joints which is explained using nucleation and grain refinement theories.
\end{abstract}

\section{INTRODUCTION}

It is well known that $\mathrm{Sn}-\mathrm{Ag}-\mathrm{Cu}$ (SAC) solder joints usually solidify after a relatively large nucleation undercooling for $\beta \operatorname{Sn}(\sim 10-30 \mathrm{~K})$ which can cause problems such as large primary intermetallic phases and only a single $\beta$ Sn nucleation event, producing single grain or cyclically-twinned joints[1-5]. For example, the large plate-like primary $\mathrm{Ag}_{3} \mathrm{Sn}$ can provide crack initiation sites and have been linked with poor mechanical behaviour of solder joints[69], and a small number of $\beta S n$ grains per joint render the joint anisotropic in thermal expansion and mechanical properties as $\beta S n$ has highly anisotropic thermophysical 
properties[1, 10-14]. When all $\beta$ Sn grains inside a ball grid array(BGA) solder joint are related by one common axis, the whole joint will respond mechanically as a single crystal along the common axis and a polycrystal along other directions[5]. Therefore, there is an interest in developing methods to control the nucleation undercooling of $\beta \mathrm{Sn}$ as well as the number and orientation of grains in solder joints.

One approach to controlling melt undercooling is microalloying SAC with a dilute addition of certain fourth elements, and these SAC-X solders ( $\mathrm{X}$ is the addition element) have been studied for more than a decade[15-19]. It has been found that Co additions are particularly effective at suppressing the nucleation undercooling of $\beta \operatorname{Sn}[20-29]$. Table 1 summarises 10 past studies on Co-microalloyed solders. It can be seen that Co additions in the range $\sim 0.02-$ $2.55 \mathrm{wt} \%$ significantly decrease the nucleation undercooling of $\beta \mathrm{Sn}$ in pure $\mathrm{Sn}$ as well as in $\mathrm{Sn}-\mathrm{Cu}, \mathrm{Sn}-\mathrm{Ag}$ and SAC solders. Most studies in Table 1 are on freestanding solder balls but two studies were performed on $\mathrm{Cu}$ substrates by Anderson et al. [25, 28], where the nucleation undercooling of $\beta \mathrm{Sn}$ is relatively high with and without the Co additions.

Based on the past work overviewed above, it seems that the nucleation of $\beta S n$ can be promoted when Co is present as a microalloying addition to SAC solder. However, importantly, past work has not explained how cobalt additions catalyse $\beta$ Sn nucleation and nor have they shown whether alloying with cobalt can lead to grain refinement (i.e. generate more $\beta$ Sn nucleation events per joint). Furthermore, past work has not explained why Co additions were ineffective when soldering to copper substrates (in Table 1). We address these questions here.

In the present study, the mechanisms by which Co catalyses $\beta$ Sn nucleation are studied in Co microalloyed Sn-3Ag-0.5Cu (SAC305). We also explore how Co-microalloying affects the $\beta \mathrm{Sn}$ nucleation location(s) and the number of $\beta \mathrm{Sn}$ nucleation events, and whether Co 
additions can be used to control the $\beta \mathrm{Sn}$ grain size in BGA-scale freestanding balls and joints. Additionally, to understand volume effects, we examine the ability of Co-microalloying to grain refine large $(60 \mathrm{~g})$ samples. 


\section{EXPERIMENTS}

SAC305, SAC305-0.05Co, and SAC305-0.4Co (wt \%) were studied. These Co concentrations were selected as they are known to be effective at minimising $\beta$ Sn nucleation undercooling based on the literature summarised in Table 1. The solders were prepared by the following steps. First, a Sn-10wt\%Co master alloy was produced by encapsulating the specified amounts of commercial purity tin (99.9\%) and Co (99.9\%) in evacuated quartz ampoules, which were then held for $168 \mathrm{~h}$ at $1200^{\circ} \mathrm{C}$. Then SAC305-0.05Co and SAC305-0.4Co solder alloys were made by mixing the required mass of the master alloy with the corresponding mass of commercial SAC305 solder bar in graphite crucibles at $500^{\circ} \mathrm{C}$. After $1 \mathrm{~h}$ holding, the melts were stirred with a preheated graphite rod to ensure master alloy dissolution. 40 gram samples were cast into a chemical analysis mould for X-Ray Fluorescence (XRF) spectroscopy analysis. The compositions of SAC305, SAC305-0.05Co, and SAC305-0.4Co are shown in Table 2.

To test for any nucleant particles present prior to $\beta$ Sn nucleation in Co microalloyed SAC305, an isothermal holding experiment was performed $5 \mathrm{~K}$ above the Co-free SAC305 liquidus temperature. Portions of the liquid SAC305-0.05Co alloy were poured into a pointedbottomed graphite crucible with inner height $90 \mathrm{~mm}$ and inner diameter $10 \mathrm{~mm}$. Then, the graphite crucible with SAC305-0.05Co alloy inside was encapsulated under argon atmosphere in a quartz tube and was placed in an air convection oven at the SAC305 liquidus $+5 \mathrm{~K}$, i.e. $222^{\circ} \mathrm{C}$. The sample was held vertically for $168 \mathrm{~h}$ at this temperature to concentrate any solid particles at the top/bottom due to floating/settling, and was then cooled in air. The bottom, middle, and top parts of the sample were examined to analyse any particles that had floated or settled during holding. 
To make 'large' $60 \mathrm{~g}$ samples, 300g of SAC305 and SAC305-0.05Co alloy was heated to $400^{\circ} \mathrm{C}$ and held for $1 \mathrm{~h}$ in graphite crucibles. Then $\sim 60 \mathrm{~g}$ was poured into a cylindrical graphite mould of inner height $30 \mathrm{~mm}$ and inner diameter $20 \mathrm{~mm}$ which had been preheated to $400^{\circ} \mathrm{C}$ and insulation was placed above and below the sample. This method was used to encourage radial heat flow, to ensure that no chill-zone formed at the mould walls, and that the temperature gradient in the liquid was very low. The cooling curve (time versus temperature) was measured with a $\mathrm{K}$ type thermocouple within a quartz tube at the centre of the sample. The cooling rate was $\sim 1 \mathrm{~K} / \mathrm{s}$ near the liquidus temperature. 4 samples of each alloy were prepared. Each sample was ground to a plane near the centre axis, polished and then etched with a solution of $4.3 \% \mathrm{HCl}$ and $8.7 \% \mathrm{FeCl}_{3}$ in distilled water for grain size measurement.

To prepare solder balls, SAC305, SAC305-0.05Co, and SAC305-0.4Co were first rolled to foils with thickness of $0.05 \mathrm{~mm} . ~ \varnothing 1.6 \mathrm{~mm}$ solder discs were produced from these foils using a punch before being cleaned in ethanol. After reflowing of these solder discs on an inert plate with RM-5 flux (Nihon Superior Co., Ltd.), solder balls were formed with a diameter of $550 \pm 25 \mu \mathrm{m}$

Some solder balls were soldered to $\mathrm{Cu}$ substrates. The substrates were masked with solder resist in order to prevent excessive spreading and the $500 \mu \mathrm{m}$ pads were coated with RM-5 flux. Joints were initially made on a hotplate and then flux residues were removed in ethanol.

Freestanding solder balls and cleaned solder joints were then reflowed in a Mettler Toledo DSC in $\mathrm{Al}$ pans under a $\mathrm{N}_{2}$ atmosphere. The heating rate was $0.17 \mathrm{~K} / \mathrm{s}$, the maximum temperature was $240^{\circ} \mathrm{C}$ and the cooling rate was $0.33 \mathrm{~K} / \mathrm{s}$. At least 10 samples were measured for each solder/substrate combination and each sample was cycled twice. Nucleation undercooling was defined as the difference between the heating onset and the cooling onset temperatures. 
To study the influence of cooling rate on the number of $\beta S n$ nucleation events in balls and joints samples were heated to $240^{\circ} \mathrm{C}$ on a STUART digital hotplate and then cooled with differing degrees of forced cooling air, which produced cooling rates of $\sim 5 \mathrm{~K} / \mathrm{s}, \sim 8 \mathrm{~K} / \mathrm{s}$, $\sim 12 \mathrm{~K} / \mathrm{s}$, and $\sim 17 \mathrm{~K} / \mathrm{s}$. At least 10 samples of balls and joints for each alloy were produced at each cooling rate.

To study cross-sections, specimens were mounted with Struers VersoCit cold mounting acrylic resin and subsequently wet-ground to 2000 grit SiC paper, and then carefully polished with colloidal silica suspension. To reveal the 3D morphology of the intermetallic compounds, the $\beta$ Sn was selectively dissolved from some samples using a solution of $5 \%$ $\mathrm{NaOH}$ and $3.5 \%$ ortho-nitrophenol in distilled water for $0.5-6 \mathrm{~h}$ at $60^{\circ} \mathrm{C}$, followed by cleaning in methanol. An OLYMPUS BX51 optical microscope and a Zeiss AURIGA field emission gun SEM (FEG-SEM) equipped with an Oxford Instruments INCA x-sight energy dispersive X-ray (EDX) and a BRUKER e-Flash ${ }^{\mathrm{HR}}$ electron backscatter diffraction (EBSD) detector were used. A BRUKER ESPRIT 2.0 software was used to analyse the obtained EBSD patterns.

In order to investigate directly the influence of primary IMCs on $\beta S n$ nucleation, a technique was developed to solder a small particle of tin powder onto the facet of a single crystal of IMC. An alloy containing the primary IMC particles was selectively etched until all $\beta$ Sn was dissolved using the same solution as was used to study the 3D morphology of IMCs. The remaining primary IMCs were collected and cleaned in methanol. A particle of $99.9 \%$ purity Sn powder with size $\sim 10 \mu \mathrm{m}$ was then placed on a single crystal IMC covered with a low viscosity flux (Stay-Clean liquid flux, HARRIS), and given a reflow cycle with the same temperature profile as used for the solder balls and joints. Samples where the tin had fully 
wet and spread on the IMC facet were analysed by SEM and the orientation relationship (OR) between $\beta$ Sn and the IMC was measured using EBSD. 


\section{RESULTS AND DISCUSSION}

3.1 $\beta$ Sn nucleation and grain refinement in $60 \mathrm{~g}$ samples

Figure 1(a) shows the bottom section of a sample of SAC305-0.05Co that had been held vertically for $168 \mathrm{~h}$ at $222^{\circ} \mathrm{C}$ (5K above the liquidus temperature of SAC305) before being cooled in air. It can be seen clearly that particles settled under gravity. These particles were not found in the top or middle sections, showing that the isothermal holding technique was successful at using gravity to concentrate a small volume fraction of denser particles at the bottom. The backscattered electron image in Figure 1(b) shows that these particles are two phases, a grey lath-shaped phase and a black block-like phase. The SEM-EDX results in Table 3 show that these two phases have compositions close to $\mathrm{Cu}_{6} \mathrm{Sn}_{5}$ and $\mathrm{CoSn}_{3}$. However, both phases contain $\mathrm{Co}, \mathrm{Cu}$ and $\mathrm{Fe}$, and are consistent with $(\mathrm{Cu}, \mathrm{Co}, \mathrm{Fe})_{6} \mathrm{Sn}_{5}$ and $(\mathrm{Co}, \mathrm{Cu}, \mathrm{Fe}) \mathrm{Sn}_{3}$ solid solutions. The measurement of $\sim 9$ at $\%$ Co substituting for $\mathrm{Cu}$ in $\mathrm{Cu}_{6} \mathrm{Sn}_{5}$ is consistent with past work that has shown that $\mathrm{Co}$ has significant solubility in $\mathrm{Cu}_{6} \mathrm{Sn}_{5}$ [3032] similar to elements such as $\mathrm{Ni}, \mathrm{Au}, \mathrm{Sb}, \mathrm{In}, \mathrm{Co}, \mathrm{Pt}, \mathrm{Pd}$ and $\mathrm{Zn}[33,34]$. The measurement of $\sim 0.6 \mathrm{at} \% \mathrm{Fe}$ in $\mathrm{Cu}_{6} \mathrm{Sn}_{5}$ is close to the detection limit in EDX but the existence of $\mathrm{Fe}$ was confirmed from clear Fe peaks in the EDX spectra of all $\mathrm{Cu}_{6} \mathrm{Sn}_{5}$ particles measured in the settled layer. This low level of $\mathrm{Fe}$ in $\mathrm{Cu}_{6} \mathrm{Sn}_{5}$ is consistent with past work that has indicated that $\mathrm{Cu}_{6} \mathrm{Sn}_{5}$ has no [35] or low solubility $(0.1 \mathrm{at} \%[30])$ of Fe. Note that Fe is an impurity in this commercial purity alloy (Table 2).

Typical EBSD patterns from the grey phase and the black phase are shown in Figure 1(c) and

(e) respectively and Figure 1(d) and (f) are the corresponding indexed EBSD patterns of $\alpha \mathrm{CoSn}_{3}$ and $\eta \mathrm{Cu}_{6} \mathrm{Sn}_{5}$. CoSn 3 has two polymorphs with structural similarities [36] and, therefore, simulated EBSD patterns of $\alpha \mathrm{CoSn}_{3}$ and $\beta \mathrm{CoSn}_{3}$ were carefully compared with the detected EBSD patterns. Band-by-band comparisons confirm that this grey phase is $\alpha \mathrm{CoSn} n_{3}$ 
(with Pearson symbol $o S 32$ ). The details can be found in the Supplementary Information. $\mathrm{Cu}_{6} \mathrm{Sn}_{5}$ has multiple polymorphs which are related to the high-temperature hexagonal $\eta \mathrm{Cu}_{6} \mathrm{Sn}_{5}$ phase in which $\mathrm{Cu}$ atoms are randomly distributed on $\mathrm{Cu} 2$ sites[37] and the polymorphs result from different forms of superstructure ordering and a resulting decrease in symmetry[38-40]. The EBSD patterns could be well-fit to each of $\eta, \eta^{\prime}, \eta^{6}, \eta^{8}$ and $\eta^{4+1}$ due to their similarities and the high-temperature $\eta \mathrm{Cu}_{6} \mathrm{Sn}_{5}$ structure has been used in Figure 1. Combining results of SEM-EDX and EBSD, these phases are identified as $\alpha \mathrm{CoSn}_{3}$ and $\mathrm{Cu}_{6} \mathrm{Sn}_{5}$. Therefore, both $\alpha \mathrm{CoSn}_{3}$ and $\mathrm{Cu}_{6} \mathrm{Sn}_{5}$ are equilibrium phases in SAC305-0.05Co at $222^{\circ} \mathrm{C}$ (before $\beta$ Sn nucleates).

Typical cooling curves of $60 \mathrm{~g}$ SAC305 and SAC305-0.05Co samples are shown in Figure 2(a) and (b). It can be seen that there is a large difference in the degree of recalescence caused by the Co addition: in SAC305 (Figure 2(a)) the recalescence after $\beta$ Sn nucleation is $\sim 14 \mathrm{~K}$ and SAC305-0.05Co has a much smaller recalescence of $\sim 0.2 \mathrm{~K}$. Table 4 summarises the characteristic temperatures of $\beta$ Sn nucleation: the minimum temperature $\left(\mathrm{T}_{\min }\right)$ before recalescence, the maximum temperature after recalescence $\left(T_{\max }\right)$, and the recalescence $(\Delta T)$ (defined as $\mathrm{T}_{\max }-\mathrm{T}_{\min }$ ). Notice that the temperature where latent heat starts to be released will be slightly higher than $T_{\min }$, but due to the difficulty of accurately measuring this temperature, it is more reliable to simply use $\mathrm{T}_{\max }-\mathrm{T}_{\min }$ as the nucleation undercooling. Therefore, as shown in Table 4, the $\beta$ Sn nucleation undercooling of SAC305 is significantly reduced from 14.6 $\mathrm{K}$ to $0.2 \mathrm{~K}$ by the $0.05 \mathrm{wt} \% \mathrm{Co}$ addition.

Typical etched 2D sections of $60 \mathrm{~g}$ samples of SAC305 and SAC305-0.05Co are shown in Figure 2(c) and (d). The $\beta$ Sn grain size is clearly much smaller in SAC305-0.05Co than in SAC305. The grain size statistics were quantified using the linear intercept method[41] as given in Table 4. With the Co addition, the mean grain size is smaller by a factor of 3.3, 
which translates into $\sim 36$ times more $\beta$ Sn grains per unit volume (assuming a log-normal grain size distribution)[42] and, therefore, $\sim 36$ times more nucleation events per unit volume.

Microstructural analysis revealed numerous $\alpha \mathrm{CoSn}_{3}$ particles in $60 \mathrm{~g}$ SAC305-0.05Co samples, as shown in the SEM image of Figure 2(e). These $\alpha \mathrm{CoSn}_{3}$ particles were evenly distributed throughout the cross-section and there were more $\alpha \mathrm{CoSn}_{3}$ particles than $\beta \mathrm{Sn}$ grains as shown in optical images of a whole sample in the Supplementary Information. It is likely that primary $\alpha \mathrm{CoSn}_{3}$ particles contribute to $\beta \mathrm{Sn}$ nucleation. However, since there are many more $\alpha \mathrm{CoSn} 3$ particles than $\beta \mathrm{Sn}$ grains and the $\alpha \mathrm{CoSn}_{3}$ particle that nucleated a $\beta \mathrm{Sn}$ grain may not be in the cross-section, it is challenging to determine which $\alpha \mathrm{CoSn}_{3}$ particles (if any) nucleated $\beta \mathrm{Sn}$. The nucleation mechanism of $\beta \mathrm{Sn}$ on $\alpha \mathrm{CoSn}_{3}$ was therefore investigated by solidifying tin directly on single crystals of $\alpha \mathrm{CoSn}_{3}$.

In all cases, the major growth facet of $\alpha \mathrm{CoSn}_{3}$ was (100) and Figure 3 shows a typical result of soldering a $\sim 10 \mu \mathrm{m}$ particle of $\mathrm{Sn}$ to the (100) facet of an $\alpha \mathrm{CoSn}_{3}$ crystal. The $\mathrm{Sn}$ particle has wet and spread into a spherical cap on the $\alpha \mathrm{CoSn}_{3}$ facet and EBSD measurements resulted in the pole figures in Figure 3. Both phases are single crystals and their unit cell orientations are shown. Note that there appear to be two (010) and (001) planes in the pole figures of a single crystal of orthorhombic $\alpha \mathrm{CoSn}_{3}$ because the indexing does not accurately distinguish between these planes at each step due to pseudosymmetry as b/c $\sim 1$. These pole figures indicate the following OR:

$(100)_{S n} \|(100)_{\operatorname{CoSn} 3}$ with $[001]_{S n} \|[001]_{\operatorname{CoS} n 3}$

EBSD measurements were conducted on $10 \mathrm{Sn} / \alpha \mathrm{CoSn}_{3}$ micro-joints, and all 10 gave the OR shown above. The misorientation angles of (100) and [001] between $\mathrm{Sn}$ and $\alpha \mathrm{CoSn}_{3}$ was 
$1.29^{\circ} \pm 1.22^{\circ}$ and $2.35^{\circ} \pm 1.25^{\circ}$ respectively, where the uncertainty has been calculated from the mean of the angles between the two lattices measured by EBSD

Based on the measured OR, the atomic match between $\beta \mathrm{Sn}$ and $\alpha \mathrm{CoSn}_{3}$ was analysed using the crystal structures in references[36, 43] as shown in Figure 4. The best match is between the (100) plane in $\beta S n$ and the (600) rather than the (100) plane in $\alpha \mathrm{CoSn}_{3}$. Note that EBSD does not differentiate between these parallel planes. It can be seen in Figure 4 that the $(100)_{\mathrm{Sn}}$ and $(600)_{\operatorname{CoSn} 3}$ planes both contain zig-zag rows and that the atomic mismatch is $1.4 \%$ between these rows and 7.5\% along these rows with similar angle. Additionally, both the $(100)_{\mathrm{Sn}}$ and $(600)_{\mathrm{CoSn} 3}$ planes are the most densely packed planes in each phase and consist of Sn atoms in $\alpha \mathrm{CoSn}_{3}$, as shown in Table 5. The relatively good lattice match suggests a relatively low interfacial energy for this $\beta \mathrm{Sn}-\alpha \mathrm{CoSn}_{3}$ orientation relationship, which would give a small wetting angle for heterogeneous nucleation and, therefore, a low nucleation undercooling. That is to say, the (100) facet of $\alpha \mathrm{CoSn}_{3}$ acts as an atomic template for $\beta \mathrm{Sn}$.

Previous research by Belyakov and Gourlay showed that $o S 20-\mathrm{XSn}_{4}(\mathrm{X}$ represents $\mathrm{Ni}, \mathrm{Pd}$, and $\mathrm{Pt}$ ) are good heterogeneous nucleants for $\beta \mathrm{Sn}[44]$. It is interesting to note that the interfacial planes measured in the current study have the same characteristics as those measured for the $\beta \mathrm{Sn} / \mathrm{XSn}$ systems. For example, the $o S 20-\mathrm{XSn}_{4}$ phases $\left(\mathrm{NiSn}_{4}, \mathrm{PdSn}_{4}\right.$ and $\left.\mathrm{PtSn}_{4}\right)$ and the $o S 32-\mathrm{XSn}_{3}$ phases $\left(\mathrm{PdSn}_{3}\right.$ and $\left.\alpha-\mathrm{CoSn}_{3}\right)$ contain tin planes with very similar atomic positions[45]. These tin planes are (h00) for $o S 32-\mathrm{XSn}_{3}$ and either $(0 \mathrm{k} 0)$ or (001) for $o S 20-\mathrm{XSn}_{4}$ depending on whether the Ccca or Aba2 space group is used respectively. The equivalent interfacial planes can be expressed as:

$(100)_{S n} \|(600)_{\operatorname{CoSn} 3}$ with $[001]_{S n} \|[001]_{\operatorname{CoSn} 3}$

$(100)_{S n} \|(008)_{P t S n 4}$ with $[001]_{S n} \|[100]_{P t S n 4}$ 
The lattice match is compared in Table 5. It can be seen that the lattice match between $(100)_{\mathrm{Sn}}$ and $(600)_{\mathrm{CoSn} 3}$ is similar to (and perhaps somewhat better than) the corresponding lattice match in the $\beta \mathrm{Sn} / \mathrm{XSn}_{4}$ systems.

Based on the reproducible measured OR between $\beta \mathrm{Sn}$ and $\alpha \mathrm{CoSn}_{3}$ (Figure 3), the relatively good lattice match associated with this OR and habit plane (Figure 4), the reduced nucleation undercooling, and the significant grain refinement in 60g SAC305-0.05Co samples (Figure 2), it can be concluded that grain refinement is due to $\beta \mathrm{Sn}$ nucleation directly on $\alpha \mathrm{CoSn}_{3}$ crystals. We note that grain refinement theories stress the importance of both solute and nucleant particles[46-49]. In this case, the $0.05 \mathrm{wt} \%$ Co addition does not significantly alter the growth restriction factor of SAC305[50] and the increment of grain refinement is mostly due to the introduction of nucleant particles.

It is interesting to note (e.g. Figure 2(e)) that there are many more $\alpha \mathrm{CoSn}_{3}$ particles than $\beta \mathrm{Sn}$ grains, which indicates that most $\alpha \mathrm{CoSn}_{3}$ particles did not nucleate a $\beta \mathrm{Sn}$ grain. This can be explained by two factors. First, each $\alpha \mathrm{CoSn}_{3}$ particle will have a characteristic undercooling required to nucleate a $\beta \mathrm{Sn}$ grain[49]. During cooling, those $\alpha \mathrm{CoSn}_{3}$ particles requiring the smallest undercooling (e.g. the largest particles[49]) will nucleate $\beta \mathrm{Sn}$ grains first and latent heat release then stifles nucleation on the other particles[47]. The second factor is the 'nucleation free zone' (NFZ) ahead of a growing $\beta$ Sn dendrite: A certain growth distance is required to generate sufficient constitutional supercooling in the liquid to nucleate the next grain. If a particle exists at a location where the constitutional supercooling is less than the required nucleation undercooling (e.g. too near another nucleation site), then nucleation will not occur on that particle[48]. Based on these two factors, the presence of many more nucleant particles than nucleated grains is a fully-expected result. 
3.2 DSC of $550 \mu \mathrm{m}$ balls and joints

Figure 5 shows the nucleation undercooling of freestanding balls and joints from DSC measurements. It is clear that the nucleation undercooling of freestanding SAC305-0.05Co $(4.6 \pm 0.8 \mathrm{~K})$ and SAC305-0.4Co $(3.9 \pm 0.8 \mathrm{~K})$ solder balls is significantly lower than that of SAC305 $(23.1 \pm 2.1 \mathrm{~K})$. Microstructural analysis confirmed that the cobalt-containing freestanding balls contain $\alpha \mathrm{CoSn}_{3}$ particles after DSC. Typical examples are shown in Figure 6 where Figure 6 (a) is a shallow-etched SAC305-0.05Co ball with numerous 2-5 $\mu$ m tile-like $\alpha \mathrm{CoSn}_{3}$ particles (Figure 6(b)) each with a (100) facet (confirmed by EBSD), similar to the single crystal of $\alpha \mathrm{CoSn}_{3}$ in Figure 3. Figure 6(c)-(f) show the appearance of $\alpha \mathrm{CoSn}_{3}$ particles in 2D sections, and it can be seen that $\alpha \mathrm{CoSn}_{3}$ settle under gravity in the DSC when cooled at $0.33 \mathrm{~K} / \mathrm{s}$.

Figure 5 shows a significant difference in the nucleation undercooling between (i) freestanding balls and (ii) solder joints on $\mathrm{Cu}$ substrates: both Co-containing solders resulted in a low undercooling in freestanding balls whereas, in joints, only SAC305-0.4Co/Cu had a low undercooling and $\mathrm{SAC} 305-0.05 \mathrm{Co} / \mathrm{Cu}$ had a relatively high nucleation undercooling that was similar to Co-free SAC305/Cu. After careful examination of microstructures such as those in Figure 7(a) and (b), it was concluded that no primary $\alpha \mathrm{CoSn}_{3}$ phase is present in SAC305-0.05Co/Cu joints. Instead, all $\mathrm{Co}$ seems to be dissolved in the $\mathrm{Cu}_{6} \mathrm{Sn}_{5}$ as $(\mathrm{Cu}, \mathrm{Co})_{6} \mathrm{Sn}_{5}$. EDX-measured compositions of primary and interfacial $\mathrm{Cu}_{6} \mathrm{Sn}_{5}$ in $\mathrm{SAC} 305-$ $0.05 \mathrm{Co} / \mathrm{Cu}$ joints are shown in Table 6. The $\mathrm{Cu}_{6} \mathrm{Sn}_{5}$ contains a significant amount of $\mathrm{Co}$, which is higher in the primary $\mathrm{Cu}_{6} \mathrm{Sn}_{5}(\sim 5 \mathrm{at} \% \mathrm{Co})$ and less in the interfacial $\mathrm{Cu}_{6} \mathrm{Sn}_{5}$ layer ( $2 \mathrm{at} \% \mathrm{Co})$. The lack of primary $\alpha \mathrm{CoSn}_{3}$ in $\mathrm{SAC} 305-0.05 \mathrm{Co} / \mathrm{Cu}$ joints indicates that dissolution of the copper substrate moved the liquid composition to a level where $\alpha \mathrm{CoSn}_{3}$ is 
not an equilibrium primary phase (i.e. from the $\mathrm{L}+\alpha(\mathrm{Co}, \mathrm{Cu}) \mathrm{Sn}_{3}+(\mathrm{Cu}, \mathrm{Co})_{6} \mathrm{Sn}_{5}$ tie triangle into the $\mathrm{L}+(\mathrm{Cu}, \mathrm{Co})_{6} \mathrm{Sn}_{5}$ two-phase region $)$.

In contrast, with higher cobalt addition, the $\mathrm{SAC} 305-0.4 \mathrm{Co} / \mathrm{Cu}$ joints had a low nucleation undercooling (Figure 5) and primary $\alpha \mathrm{CoSn}_{3}$ particles were present in the bulk solder after DSC (Figure 7(c)-(e)). As shown in Figure 7(e), $\alpha \mathrm{CoSn}_{3}$ particles in SAC305-0.4Co/Cu joints have a tile-like morphology and are similar to those in 60g SAC305-0.05Co samples and SAC305-0.05Co DSC reflowed freestanding balls. Combining Figure 5 with the microstructural observations in Figure 6 and Figure 7, it can be concluded that the low nucleation undercooling occurs when $\alpha \operatorname{CoSn}_{3}$ particles are present and is due to heterogeneous nucleation of $\beta \mathrm{Sn}$ on $\alpha \mathrm{CoSn}_{3}$ particles, similar to the $60 \mathrm{~g}$ samples in Figure 2.

Examination of $>50$ solder balls and joints reflowed in the DSC with a cooling rate of $0.33 \mathrm{~K} / \mathrm{s}$ showed that all had one of three types of $\beta S n$ grain structure, as summarised in Figure 8 and Figure 9. Figure 8 overviews the three 'types' where different colours in each EBSD $\beta$ Sn orientation map are defined in the pole figures and by the unit cell wireframes. Figure $8(a)$ and (d) show the typical single-grain structure in balls and joints, where there is a single $\beta$ Sn orientation and low angle boundaries $<15^{\circ}$. Figure $8(\mathrm{~b})$ and (e) show the typical two-orientation structure in balls and joints, where the two grains are related by a common [100] or [010] axis and $\sim 60^{\circ}$ angle, which is indicative of $\{101\}$ or $\{301\}$ twinning. This can be seen by noticing that, in all $\{100\}$ pole figures in Figure $8(\mathrm{~b})$ and (e) the two grains share a common plane and all misorientation angles are either $\sim 60^{\circ}$ or low angle boundaries. Figure 8(c) and (f) show the typical three-orientation structure in balls and joints, where the three grains are again related by a common [100] or [010] axis and $60^{\circ}$ twinning angle. It seems likely that the two-orientation and three-orientation twinned structures may be similar in 3D and the apparent differences between Figure 8(b) and (c)(or Figure 8(e) and (f) ) may be a 
sectioning effect. These grain structures are similar to previous work on SAC solders $[4,5]$. The percentages of these three $\beta \mathrm{Sn}$ structures in balls and joints for each alloy are summarised in Figure 9 based on 30 samples for each composition. There is no clear effect of solder composition on the formation of single-grain structures and no simple trend was found between the individual undercooling of a ball/joint and the single-grain structure. It can also be seen that the solders solidified with the single grain structure more frequently in joints than the freestanding balls. Importantly, it can be concluded that all three structures in Figure 8 are the result of a single independent nucleation event (e.g. on a single $\alpha \mathrm{CoSn}_{3}$ particle in the cases where they are present) because it is improbable that $\beta \mathrm{Sn}$ grains would nucleate in two distinct locations and impinge on one another with a twin orientation relationship. That is to say, all DSC samples cooled at $0.33 \mathrm{~K} / \mathrm{s}$ solidified with only one independent $\beta \mathrm{Sn}$ nucleation event despite the markedly reduced nucleation undercooling (Figure 5) when $\alpha \mathrm{CoSn}_{3}$ particles are present.

In addition to reducing the nucleation undercooling, the presence of $\alpha \mathrm{CoSn}_{3}$ particles had a significant influence on the nucleation location in joints. In SAC solders, it is often possible to identify the approximate location where $\beta$ Sn nucleated [5] (i) from the growth direction and lengthscale of the dendrites (dendrites are finer near the nucleation site where dendrite growth occurred at higher undercooling before latent heat release increased the interface temperature), (ii) from the twin boundaries (which often 'point back' towards the nucleation location), and (iii) because there is usually only one nucleation event which simplifies the interpretation. Using this identification technique, a clear difference was found between $\mathrm{SAC} 305 / \mathrm{Cu}$ and $\mathrm{SAC} 305-0.4 \mathrm{Co} / \mathrm{Cu}$ joints: in $\mathrm{SAC} 305 / \mathrm{Cu}, \beta \mathrm{Sn}$ grows from (or from near) the $\mathrm{Cu}_{6} \mathrm{Sn}_{5}$ layer (Figure 8(e) and (f) and Figure 10(a) and (c)), whereas, in SAC305$0.4 \mathrm{Co} / \mathrm{Cu}, \beta \mathrm{Sn}$ nucleates in the bulk liquid in a region containing $\alpha \mathrm{CoSn}_{3}$ particles (Figure 
10(b), (d) and (e)). Note that Figure $8(\mathrm{e})$ is a SAC305-0.05Co/Cu joint and that, at the $0.05 \mathrm{Co}$ level, no $\alpha \operatorname{CoSn}_{3}$ formed as discussed earlier and, therefore, $\beta \mathrm{Sn}$ nucleation is similar to Cofree SAC305/Cu joints. Note also that, in SAC305-0.4Co/Cu joints, $\alpha \mathrm{CoSn} n_{3}$ particles were observed near the nucleation location. For example, in Figure 10(b), nucleation occurred near to "2 o'clock" and $\alpha \mathrm{CoSn}_{3}$ particles exist in that region (Figure $10(\mathrm{e})$ ) as well as in a settled layer. It is important to note that, in many joints, it was not possible to determine the nucleation location but, whenever, there was a beachball structure with a sectioning plane near the intersection of the twinned grains, the nucleation location was always at/near the $\mathrm{Cu}_{6} \mathrm{Sn}_{5}$ layer in $\mathrm{SAC} 305 / \mathrm{Cu}$ and $\mathrm{SAC} 305-0.05 \mathrm{Co} / \mathrm{Cu}$ joints, and most commonly in the bulk away from the layer in SAC305-0.4Co/Cu joints, similar to Figure 10. 
3.3 Solidification of $550 \mu \mathrm{m}$ balls and joints at higher cooling rates

The distribution of $\beta$ Sn grain orientations was more complex at high cooling rate than in the slow cooled DSC samples of Figure 8. Since this is a study of nucleation, we are interested in the number of independent grains in each cross-section. We define independent grains as those that are not related to their neighbours by a special high-angle grain boundary (e.g. twins or coincident site lattice (CSL) boundaries), nor a low angle grain boundary. In $\beta$ Sn, most twins and CSL boundaries have a common $<100>,<001>$ or $<110>\operatorname{direction}[5,51]$ and, therefore, we identified independent grains by first checking for any common $<100>$, $<001>$ or $<110>$ axes and then, if necessary, checking whether the misorientation around that axis is consistent with a known twin or CSL boundary. Figure 11(a)-(f) are typical examples from this analysis, where both the common axis and the misorientations of the high angle boundaries are highlighted. These examples contain 3, 2, 3, 3, 2, 5 orientations and 1, 2, 2, 1, 2, 3 independent grains respectively. Further details are given in Figure Caption 11.

A summary of the number of independent $\beta S n$ grains in balls and joints is given in the pie charts in Figure 11(g) for the three solder compositions, at four cooling rates spanning 5$\sim 17 \mathrm{~K} / \mathrm{s}$ (representing $>200$ samples). Note that $\mathrm{SAC} 305-0.05 \mathrm{Co} / \mathrm{Cu}$ joints were not studied at this range of cooling rates because they did not contain $\alpha \mathrm{CoSn}_{3}$ in DSC studies (as discussed in section 3.2). It can be seen in Figure 11(g) that SAC305 balls and SAC305/Cu joints contained only a single independent $\beta$ Sn grain at all cooling rates studied. Since this was measured in the cross-section of multiple samples $(>80)$, it is very likely that there was only one nucleation event in the whole volume in each case. In contrast, SAC305-Co balls and SAC305-0.4Co/Cu joints contained either 1,2 or 3 independent grains for cooling rates of $\sim 5 \mathrm{~K} / \mathrm{s}$ and higher. In this case, it is more difficult to reliably link the number of independent grains in cross-sections to the number of grains in the whole sample volume, but it is clear 
that there were multiple nucleation events in many samples when $\alpha \mathrm{CoSn}_{3}$ particles were present and the cooling rate was $\geq \sim 5 \mathrm{~K} / \mathrm{s}$. Similar to the slow cooled DSC joints, there was often evidence that $\beta \mathrm{Sn}$ nucleated on an $\alpha \mathrm{CoSn}_{3}$ particle in the bulk liquid in SAC305$0.4 \mathrm{Co} / \mathrm{Cu}$ joints and on the $\mathrm{Cu}_{6} \mathrm{Sn}_{5}$ layer in $\mathrm{SAC} 305 / \mathrm{Cu}$ joints as shown in Figure 10(c)-(d). 
3.4 The role of cooling rate and sample volume

The promotion of multiple nucleation events in SAC305-Co freestanding balls and SAC305$0.4 \mathrm{Co} / \mathrm{Cu}$ joints with increased cooling rate is likely to be due to three factors. First, it is common for cooling rate-induced grain refinement to be explained and modelled in terms of a slightly increased maximum undercooling before the onset of recalescence due to the increased external heat flux[47, 49, 52]. This enables a higher proportion of the nucleant particles to trigger nucleation events before recalescence stifles further nucleation and, therefore, decreases the grain size[49]. We could not confirm whether this is true for $550 \mu \mathrm{m}$ solder balls and joints containing $\alpha \mathrm{CoSn}_{3}$ due to the difficulty of reliably measuring undercooling in small balls cooled at $\geq \sim 5 \mathrm{~K} / \mathrm{s}$, but it is likely to be the case

Second, the cooling rate affects the solute boundary layer in the liquid ahead of the dendrite envelope and, therefore, the growth distance required to generate sufficient constitutional supercooling (CS) to trigger another nucleation event $[46,48,53]$. This can be understood with reference to Figure 12(c) and (d): After the first nucleation event, the growing dendrite (or twinned dendrite) will develop a solute boundary layer and CS ahead of the dendrite envelope. If the CS reaches the required nucleation undercooling in a region where an $\alpha \mathrm{CoSn}_{3}$ particle is present, then nucleation is expected to be triggered on that $\alpha \mathrm{CoSn}_{3}$ particle. Since the nucleation undercooling is relatively low in samples containing $\alpha \mathrm{CoSn}_{3}$, the recalescence is relatively low and the dendrite tip velocity will depend mostly on the external heat flux. Thus, increasing the cooling rate will create a steeper concentration gradient ahead of the dendrite envelope and decrease the dendrite growth distance required to generate sufficient CS in the liquid to trigger the next nucleation event. For the case in Figure 12(a) and (b), nucleation is not triggered on a second $\alpha \mathrm{CoSn}_{3}$ particle but, for high enough interface velocity in the presence of $\alpha \mathrm{CoSn}_{3}$ particles, the nucleation free zone is expected to 
be smaller than the ball diameter, resulting in additional nucleation events. This may have been the case for the samples in Figure 11(b), (c), (e) and (f). In SAC305/Cu, where there are no $\alpha \mathrm{CoSn}_{3}$ particles, the required nucleation undercooling is too high to be able to trigger a second nucleation event by this mechanism.

Third, the cooling rate can alter the nucleant particles. In this study, during cooling at 0.33 $\mathrm{K} / \mathrm{s}$ in the DSC, the $\alpha \mathrm{CoSn}_{3}$ particles settled into a layer (Figure 6 and Figure 7). In contrast, at cooling rates $\geq \sim 5 \mathrm{~K} / \mathrm{s}$, the $\alpha \mathrm{CoSn}_{3}$ particles were evenly distributed throughout the sample volume (e.g. Figure 12(a)) as they did not have time to settle under gravity. Thus, $\alpha \mathrm{CoSn}{ }_{3}$ particles were present away from the initial nucleation event where they could trigger additional nucleation events both by being less affected by latent heat release from the first $\beta$ Sn crystal and by being in the liquid with highest level of CS. Note that the size and morphology of the $\alpha \mathrm{CoSn}_{3}$ particles were not significantly altered by the increased cooling rate and, therefore, $\alpha \operatorname{CoSn}_{3}$ size differences are unlikely to be a factor in the increased number of $\beta$ Sn nucleation events with cooling rate.

Figure 2 shows that Co-microalloying caused significant grain refinement in large $(60 \mathrm{~g})$ samples. However, in $550 \mu \mathrm{m}$ solder balls and joints, Co-microalloying caused only up to 3 independent grains in a cross-section (Figure 11) which cannot be described as strong grain refinement. One factor behind this is clearly the small solder volume: a very high number of nucleation events per unit volume would be required to significantly grain refine a small volume by a nucleation mechanism, and a short nucleation free zone would be required to trigger new nucleation events by a CS mechanism. Note also that the development of constitutionally supercooled liquid ahead of the dendrite envelope is hindered by the small volume because the proximity of the ball surface (e.g. Figure 12) will promote a 'final 
transient' in the solute boundary layer and reduce the maximum constitutional supercooling present.

A further factor is the influence of the sample volume on the nucleation undercooling. Figure 13 shows that both SAC305 and SAC305-0.05Co solder balls have a mean nucleation undercooling and standard deviation that increases with decreasing sample volume, and this can also be seen in Figure 5 when comparing 60g samples with solder balls. This effect is stronger in Co-free SAC305, but the increase in undercooling in SAC305-0.05Co is significant with $\Delta \mathrm{T} \sim 0.2 \mathrm{~K}$ in $60 \mathrm{~g}$ samples and $\Delta \mathrm{T}>10 \mathrm{~K}$ in $200 \mu \mathrm{m}$ balls. Note that $\alpha \mathrm{CoSn}_{3}$ particles larger than $2 \mu \mathrm{m}$ were present at all solder volumes. It is well known that SAC305 exhibits the volume versus nucleation undercooling relationship in Figure 13 and that smaller volumes result in a much larger variance in nucleation undercooling $[3,4,54]$. The fact that SAC305-0.05Co also shows this trend provides some insight into the $\beta$ Sn nucleation process on $\alpha \mathrm{CoSn}_{3}$ particles: it implies the probabilistic thermal nature of classical heterogeneous nucleation theory where the nucleation rate depends on the formation of a critical nucleus through structural fluctuations in the liquid near the nucleant particle. Reducing the sample volume reduces the number of $\alpha \mathrm{CoSn}_{3}$ particles (and the surface area of $\alpha \mathrm{CoSn}_{3}$-L interface) which increases the characteristic time to the first nucleation event during continuous cooling. This is in contrast to potent nucleant particles in other systems (such as $\mathrm{Al}_{3} \mathrm{Ti}$ in $\mathrm{Al}$ alloys which also requires nucleation undercoolings similar to the $0.2 \mathrm{~K}$ measured here in $60 \mathrm{~g}$ samples (Table 4)) where the formation of a critical nucleus on the nucleant particle is not the controlling factor and, rather, free growth from the particles is thought to determine the nucleation process[42]. As a result of this size effect, only relatively weak grain refinement can be generated by Co-microalloying in volumes relevant to electronic interconnections, while significant grain refinement is achievable in large (60g) samples (Figure 2). 


\section{Conclusions}

The mechanisms of $\beta \mathrm{Sn}$ nucleation and grain refinement have been studied in Comicroalloyed SAC305 solder. The following conclusions can be drawn:

(1) Co microalloying substantially reduced the nucleation undercooling for $\beta$ Sn because $\alpha \mathrm{CoSn}_{3}$ particles form in the melt which are relatively potent nucleation catalysts for $\beta \mathrm{Sn}$.

(2) $\alpha \mathrm{CoSn}_{3}$ crystals grew with (100) as the major facet and a reproducible orientation relationship was measured between $\beta \mathrm{Sn}$ and the (100) facet of $\alpha \operatorname{CoSn}_{3}$, which has a planar lattice mismatch of $\sim 4 \%$. The $\mathrm{OR}$ is:

$(100)_{S n} \|(100)_{\operatorname{CoSn} 3}$ with $[001]_{S n} \|[001]_{\operatorname{CoSn} 3}$

(3) In large (60g) samples, Co microalloying of SAC305 caused significant grain refinement by decreasing the $\beta$ Sn grain size by a factor of 3.3 .

(4) In volumes relevant to electronic soldering, Co microalloying of SAC305 increased the number of $\beta$ Sn nucleation events when the cooling rate was $\geq \sim 5 \mathrm{~K} / \mathrm{s}$. However, there were only up to $2-3$ independent grains in the $2 \mathrm{D}$ sections of $550 \mu \mathrm{m}$ balls and joints (compared with 1 nucleation event in Co-free SAC305 under the same conditions).

(5) In solder joints on $\mathrm{Cu}$ substrates, Co microalloying was often ineffective at reducing undercooling or increasing the number of nucleation events. This was shown to be because $\mathrm{Cu}$ dissolution moves the liquid composition to a level where $\alpha \mathrm{CoSn}_{3}$ is not an equilibrium primary phase. Thus, significantly higher Co-contents were required to suppress undercooling and trigger additional nucleation events in joints on $\mathrm{Cu}$ than in freestanding solder balls.

(6) For a Co level where $\alpha \mathrm{CoSn}_{3}$ forms in joints on $\mathrm{Cu}$ substrates, the $\alpha \mathrm{CoSn}_{3}$ was effective at changing the nucleation location. In $\mathrm{SAC} 305 / \mathrm{Cu}$ and $\mathrm{SAC} 305-0.05 \mathrm{Co} / \mathrm{Cu}$ joints, $\beta \mathrm{Sn}$ 
always nucleated on (or near) the $\mathrm{Cu}_{6} \mathrm{Sn}_{5}$ reaction layer. In SAC305-0.4Co/Cu joints, $\beta \mathrm{Sn}$ most commonly nucleated on $\alpha \operatorname{CoSn}_{3}$ particles in the bulk liquid. 


\section{REFERENCES}

[1] D. Swenson, The effects of suppressed beta tin nucleation on the microstructural evolution of lead-free solder joints, J Mater Sci-Mater El, 18 (2007) 39-54.

[2] T.-K. Lee, B. Zhou, L. Blair, K.-C. Liu, T. Bieler, Sn-Ag-Cu Solder Joint Microstructure and

Orientation Evolution as a Function of Position and Thermal Cycles in Ball Grid Arrays Using

Orientation Imaging Microscopy, J Electron Mater, 39 (2010) 2588-2597.

[3] R. Kinyanjui, L. Lehman, L. Zavalij, E. Cotts, Effect of sample size on the solidification temperature and microstructure of SnAgCu near eutectic alloys, J Mater Res, 20 (2005) 2914-2918.

[4] B. Arfaei, N. Kim, E.J. Cotts, Dependence of Sn Grain Morphology of Sn-Ag-Cu Solder on

Solidification Temperature, J Electron Mater, 41 (2012) 362-374.

[5] L.P. Lehman, Y. Xing, T.R. Bieler, E.J. Cotts, Cyclic twin nucleation in tin-based solder alloys, Acta Mater, 58 (2010) 3546-3556.

[6] S.K. Kang, D.Y. Shih, D. Leonard, D.W. Henderson, T. Gosselin, S.I. Cho, J. Yu, W.K. Choi, Controlling $\mathrm{Ag} 3 \mathrm{Sn}$ plate formation, in near-ternary-eutectic $\mathrm{Sn}-\mathrm{Ag}-\mathrm{Cu}$ solder by minor $\mathrm{Zn}$ alloying, Jom-Us, 56 (2004) 34-38.

[7] Y. Takamatsu, H. Esaka, K. Shinozuka, Formation Mechanism of Eutectic Cu6Sn5 and Ag3Sn after Growth of Primary beta-Sn in Sn-Ag-Cu Alloy, Mater Trans, 52 (2011) 189-195.

[8] K.S. Kim, S.H. Huh, K. Suganuma, Effects of intermetallic compounds on properties of Sn-Ag-Cu lead-free soldered joints, J Alloy Compd, 352 (2003) 226-236.

[9] J.M. Song, J.J. Lin, C.F. Huang, H.Y. Chuang, Crystallization, morphology and distribution of Ag3Sn in $\mathrm{Sn}-\mathrm{Ag}-\mathrm{Cu}$ alloys and their influence on the vibration fracture properties, Mat Sci Eng a-Struct, 466 (2007) 9-17.

[10] S.H. Yang, Y.H. Tian, C.Q. Wang, Investigation on Sn grain number and crystal orientation in the Sn-Ag-Cu/Cu solder joints of different sizes, J Mater Sci-Mater El, 21 (2010) 1174-1180.

[11] A. LaLonde, D. Emelander, J. Jeannette, C. Larson, W. Rietz, D. Swenson, D.W. Henderson, Quantitative metallography of beta-Sn dendrites in $\mathrm{Sn}-3.8 \mathrm{Ag}-0.7 \mathrm{Cu}$ ball grid array solder balls via electron backscatter diffraction and polarized light microscopy, J Electron Mater, 33 (2004) 15451549.

[12] L.P. Lehman, S.N. Athavale, T.Z. Fullem, A.C. Giamis, R.K. Kinyanjui, M. Lowenstein, K. Mather, R. Patel, D. Rae, J. Wang, Y. Xing, L. Zavalij, P. Borgesen, E.J. Cotts, Growth of Sn and intermetallic compounds in Sn-Ag-Cu solder, J Electron Mater, 33 (2004) 1429-1439.

[13] D.W. Henderson, J.J. Woods, T.A. Gosselin, J. Bartelo, D.E. King, T.M. Korhonen, M.A. Korhonen, L.P. Lehman, S.K. Kang, P. Lauro, D.Y. Shih, C. Goldsmith, K.J. Puttlitz, The microstructure of Sn in near-eutectic Sn-Ag-Cu alloy solder joints and its role in thermomechanical fatigue, J Mater Res, 19 (2004) 1608-1612.

[14] P. Sarobol, W.-H. Chen, A.E. Pedigo, P. Su, J.E. Blendell, C.A. Handwerker, Effects of local grain misorientation and $\beta$-Sn elastic anisotropy on whisker and hillock formation, J Mater Res, 28 (2013) 747-756.

[15] I.E. Anderson, J.C. Foley, B.A. Cook, J. Harringa, R.L. Terpstra, O. Unal, Alloying effects in neareutectic Sn-Ag-Cu solder alloys for improved microstructural stability, J Electron Mater, 30 (2001) 1050-1059.

[16] I.E. Anderson, Development of Sn-Ag-Cu and $\mathrm{Sn}-\mathrm{Ag}-\mathrm{Cu}-\mathrm{X}$ alloys for $\mathrm{Pb}$-free electronic solder applications, J Mater Sci-Mater El, 18 (2007) 55-76.

[17] K.S. Kim, S.H. Huh, K. Suganuma, Effects of fourth alloying additive on microstructures and tensile properties of Sn-Ag-Cu alloy and joints with Cu, Microelectron Reliab, 43 (2003) 259-267. [18] L. Sun, L. Zhang, Properties and Microstructures of Sn-Ag-Cu-X Lead-Free Solder Joints in Electronic Packaging, Advances in Materials Science and Engineering, 2015 (2015) 16.

[19] O. Krammer, T. Garami, Reliability investigation of low silver content micro-alloyed SAC solders, in: Electronics Technology (ISSE), 2012 35th International Spring Seminar on, 2012, pp. 149-154. 
[20] M.G. Cho, H.Y. Kim, S.K. Seo, H.M. Lee, Enhancement of heterogeneous nucleation of beta-Sn phases in Sn-rich solders by adding minor alloying elements with hexagonal closed packed structures, Appl Phys Lett, 95 (2009).

[21] S.K. Kang, C. Moon-Gi, P. Lauro, S. Da-Yuan, Critical Factors Affecting the Undercooling of Pbfree, Flip-Chip Solder Bumps and In-situ Observation of Solidification Process, in: Electronic Components and Technology Conference, 2007. ECTC '07. Proceedings. 57th, 2007, pp. 1597-1603. [22] D. Kim, M. Cho, S.-K. Seo, H. Lee, Effects of Co Addition on Bulk Properties of Sn-3.5Ag Solder and Interfacial Reactions with Ni-P UBM, J Electron Mater, 38 (2009) 39-45.

[23] J.M. Song, C.F. Huang, H.Y. Chuang, Microstructural characteristics and vibration fracture properties of Sn-Ag-Cu-TM (TM = Co, Ni, and Zn) alloys, J Electron Mater, 35 (2006) 2154-2163. [24] I. de Sousa, D.W. Henderson, L. Patry, S.K. Kang, D.Y. Shih, The influence of low level doping on the thermal evolution of SAC alloy solder joints with Cu pad structures, 56th Electronic Components \& Technology Conference 2006, Vol 1 and 2, Proceedings, (2006) 1454-1461.

[25] I.E. Anderson, J. Walleser, J.L. Harringa, Observations of nucleation catalysis effects during solidification of SnAgCuX solder joints, Jom-Us, 59 (2007) 38-43.

[26] F. Cheng, H. Nishikawa, T. Takemoto, Microstructural and mechanical properties of Sn-Ag-Cu lead-free solders with minor addition of Ni and/or Co, J Mater Sci, 43 (2008) 3643-3648.

[27] G. Parks, A. Faucett, C. Fox, J. Smith, E. Cotts, The Nucleation of Sn in Undercooled Melts: The Effect of Metal Impurities, Jom-Us, 66 (2014) 2311-2319.

[28] I.E. Anderson, J.W. Walleser, J.L. Harringa, F. Laabs, A. Kracher, Nucleation Control and Thermal Aging Resistance of Near-Eutectic Sn-Ag-Cu-X Solder Joints by Alloy Design, J Electron Mater, 38 (2009) 2770-2779.

[29] L. Liu, X.L. Ma, Q.S. Huang, J.F. Li, X.H. Cheng, Y.H. Zhou, Solidification process and microstructure evolution of bulk undercooled Co-Sn alloys, T Nonferr Metal Soc, 23 (2013) 289-293. [30] Y.W. Wang, Y.W. Lin, C.T. Tu, C.R. Kao, Effects of minor Fe, Co, and $\mathrm{Ni}$ additions on the reaction between SnAgCu solder and Cu, J Alloy Compd, 478 (2009) 121-127.

[31] M. Amagai, A study of nanoparticles in Sn-Ag based lead free solders, Microelectron Reliab, 48 (2008) 1-16.

[32] F. Gao, T. Takemoto, H. Nishikawa, Effects of $\mathrm{Co}$ and Ni addition on reactive diffusion between Sn-3.5 Ag solder and Cu during soldering and annealing, Materials Science and Engineering: A, 420 (2006) 39-46.

[33] T. Laurila, V. Vuorinen, M. Paulasto-Kröckel, Impurity and alloying effects on interfacial reaction layers in Pb-free soldering, Materials Science and Engineering: R: Reports, 68 (2010) 1-38.

[34] D.K. Mu, S.D. McDonald, J. Read, H. Huang, K. Nogita, Critical properties of Cu6Sn5 in electronic devices: Recent progress and a review, Current Opinion in Solid State and Materials Science, 20 (2016) 55-76.

[35] T. Laurila, J. Hurtig, V. Vuorinen, J.K. Kivilahti, Effect of Ag, Fe, Au and $\mathrm{Ni}$ on the growth kinetics of Sn-Cu intermetallic compound layers, Microelectron Reliab, 49 (2009) 242-247.

[36] A. Lang, W. Jeitschko, Two new phases in the system cobalt-tin: the crystal structures of a-and ß-CoSn3, Zeitschrift fuer Metallkunde, 87 (1996) 759-764.

[37] K. Nogita, C.M. Gourlay, T. Nishimura, Cracking and phase stability in reaction layers between Sn-Cu-Ni solders and Cu substrates, Jom-Us, 61 (2009) 45-51.

[38] A.-K. Larsson, L. Stenberg, S. Lidin, The superstructure of domain-twinned n'-Cu6Sn5, Acta Crystallographica Section B: Structural Science, 50 (1994) 636-643.

[39] S. Lidin, A.-K. Larsson, A Survey of Superstructures in Intermetallic NiAs-Ni2In-Type Phases, Journal of Solid State Chemistry, 118 (1995) 313-322.

[40] Y.Q. Wu, J.C. Barry, T. Yamamoto, Q.F. Gu, S.D. McDonald, S. Matsumura, H. Huang, K. Nogita, A new phase in stoichiometric Cu6Sn5, Acta Mater, 60 (2012) 6581-6591.

[41] A. E112-13, Standard test methods for determining average grain size, (2014).

[42] A.L. Greer, A.M. Bunn, A. Tronche, P.V. Evans, D.J. Bristow, Modelling of inoculation of metallic melts: application to grain refinement of aluminium by Al-Ti-B, Acta Mater, 48 (2000) 2823-2835. 
[43] H.e.T. Swanson, E., Standard X-ray diffraction powder patterns, National Bureau of Standards(U.S.), 569 (1953) 1-95.

[44] S.A. Belyakov, C.M. Gourlay, Heterogeneous nucleation of $\beta S n$ on NiSn4, PdSn4 and PtSn4, Acta Mater, 71 (2014) 56-68.

[45] J. Nylen, F.J. Garcia Garcia, B.D. Mosel, R. Poettgen, U. Haeussermann, Structural Relationships, Phase Stability and Bonding of Compounds PdSnn $(n=2,3$, 4), Solid state Sciences, 6 (2004) 147-155. [46] D. Shu, B. Sun, J. Mi, P.S. Grant, A quantitative study of solute diffusion field effects on heterogeneous nucleation and the grain size of alloys, Acta Mater, 59 (2011) 2135-2144.

[47] I. Maxwell, A. Hellawell, A simple model for grain refinement during solidification, Acta Metallurgica, 23 (1975) 229-237.

[48] D.H. StJohn, M. Qian, M.A. Easton, P. Cao, The Interdependence Theory: The relationship between grain formation and nucleant selection, Acta Mater, 59 (2011) 4907-4921.

[49] T.E. Quested, A.L. Greer, The effect of the size distribution of inoculant particles on as-cast grain size in aluminium alloys, Acta Mater, 52 (2004) 3859-3868.

[50] Thermo-Calc, TCSLD Database version 3.0, in, 2015.

[51] A.U. Telang, T.R. Bieler, The orientation imaging microscopy of lead-free Sn-Ag solder joints, Jom-Us, 57 44-49.

[52] J. Zou, M. Rappaz, V.R. Voller, M.S. Stachowicz, B.G. Thomas, Experiment and Modeling of Gray Cast Iron Solidification. Part I: Uniformly Solidified Castings, in, TMS Publ., 1991, pp. 335.

[53] J.D. Hunt, Steady state columnar and equiaxed growth of dendrites and eutectic, Mater Sci Eng, 65 (1984) 75-83.

[54] C.M. Gourlay, S.A. Belyakov, Z.L. Ma, J.W. Xian, Nucleation and Growth of Tin in Pb-Free Solder Joints, JOM, 67 (2015) 2383-2393. 
Table 1 Summary of DSC data from the literature on the influence of cobalt additions on the nucleation undercooling for $\beta \mathrm{Sn}$. ESD = equivalent sphere diameter calculated from the sample mass using a density of $7285 \mathrm{~kg} \mathrm{~m}^{-3}$

\begin{tabular}{|c|c|c|c|c|c|c|}
\hline \multirow{2}{*}{$\begin{array}{c}\text { Base alloy } \\
{[\mathrm{wt} \%]}\end{array}$} & \multirow{2}{*}{$\begin{array}{c}\text { Co addition } \\
{[\mathrm{wt} \%]}\end{array}$} & \multirow{2}{*}{$\begin{array}{c}\text { Size (ESD) } \\
{[\mu \mathrm{m}]}\end{array}$} & \multirow{2}{*}{$\begin{array}{c}\text { Cooling rate } \\
{[\mathrm{K} / \mathrm{s}]}\end{array}$} & \multicolumn{2}{|c|}{$\Delta \mathrm{T}_{\text {nuc }}[\mathrm{K}]$} & \multirow[t]{2}{*}{ Ref. } \\
\hline & & & & Without Co & With Co & \\
\hline \multicolumn{7}{|c|}{ Freestanding solder balls } \\
\hline $\operatorname{Sn}(99.99 \%)$ & 0.2 & 1080 & 0.1 & 31.2 & 6.3 & {$[20]$} \\
\hline $\operatorname{Sn}(99.9999 \%)$ & 0.1 & 807 & 0.33 & 75.0 & 3.0 & [27] \\
\hline $\operatorname{Sn}(99.9999 \%)$ & 0.15 & 807 & 0.33 & 75.0 & 2.6 & [27] \\
\hline $\operatorname{Sn}(99.9999 \%)$ & 0.2 & 807 & 0.33 & 75.0 & 4.0 & [27] \\
\hline $\operatorname{Sn}(99.9999 \%)$ & 0.5 & 807 & 0.33 & 75.0 & 2.8 & {$[27]$} \\
\hline $\operatorname{Sn}(99.9999 \%)$ & 1 & 807 & 0.33 & 75.0 & 4.4 & {$[27]$} \\
\hline $\operatorname{Sn}(99.9999 \%)$ & 1.51 & 807 & 0.33 & 75.0 & 4.4 & [27] \\
\hline $\operatorname{Sn}(99.9999 \%)$ & 2.03 & 807 & 0.33 & 75.0 & 4.9 & {$[27]$} \\
\hline $\operatorname{Sn}(99.9999 \%)$ & 2.55 & 807 & 0.33 & 75.0 & 4.4 & [29] \\
\hline $\mathrm{Sn}-0.9 \mathrm{Cu}$ & 0.2 & 1280 & 0.1 & 28.9 & 4.7 & {$[21]$} \\
\hline $\mathrm{Sn}-3.5 \mathrm{Ag}$ & 0.01 & 923 & 0.1 & 30.7 & 30.1 & {$[22]$} \\
\hline $\mathrm{Sn}-3.5 \mathrm{Ag}$ & 0.02 & 923 & 0.1 & 30.7 & 13.7 & [22] \\
\hline $\mathrm{Sn}-3.5 \mathrm{Ag}$ & 0.03 & 923 & 0.1 & 30.7 & 7.0 & [22] \\
\hline $\mathrm{Sn}-3.5 \mathrm{Ag}$ & 0.05 & 923 & 0.1 & 30.7 & 4.3 & [22] \\
\hline $\mathrm{Sn}-3.5 \mathrm{Ag}$ & 0.1 & 923 & 0.1 & 30.7 & 5.3 & [22] \\
\hline $\mathrm{Sn}-3.5 \mathrm{Ag}$ & 0.4 & 923 & 0.1 & 30.7 & 6.1 & [22] \\
\hline $\mathrm{Sn}-3.5 \mathrm{Ag}$ & 0.7 & 923 & 0.1 & 30.7 & 5.6 & {$[22]$} \\
\hline $\mathrm{Sn}-3.3 \mathrm{Ag}-0.5 \mathrm{Cu}$ & 0.5 & -- & 0.017 & 28.1 & 8.9 & {$[23]$} \\
\hline $\mathrm{Sn}-3.0 \mathrm{Ag}-0.5 \mathrm{Cu}$ & 0.3 & 635 & 1.3 & 47.0 & 7.5 & [24] \\
\hline $\mathrm{Sn}-3.0 \mathrm{Ag}-0.95 \mathrm{Cu}$ & 0.05 & -- & 1.5 & 27.3 & 6.6 & {$[25]$} \\
\hline $\mathrm{Sn}-3.0 \mathrm{Ag}-0.95 \mathrm{Cu}$ & 0.1 & -- & 1.5 & 27.3 & 7.7 & [25] \\
\hline $\mathrm{Sn}-3.0 \mathrm{Ag}-0.95 \mathrm{Cu}$ & 0.15 & -- & 1.5 & 27.3 & 10.7 & {$[25]$} \\
\hline $\mathrm{Sn}-3.0 \mathrm{Ag}-0.95 \mathrm{Cu}$ & 0.05 & -- & 0.17 & 17.0 & 19.2 & {$[25]$} \\
\hline $\mathrm{Sn}-3.0 \mathrm{Ag}-0.95 \mathrm{Cu}$ & 0.1 & -- & 0.17 & 17.0 & 2.5 & [25] \\
\hline $\mathrm{Sn}-3.0 \mathrm{Ag}-0.95 \mathrm{Cu}$ & 0.15 & -- & 0.17 & 17.0 & 5.7 & {$[25]$} \\
\hline $\mathrm{Sn}-3.0 \mathrm{Ag}-0.5 \mathrm{Cu}$ & 0.2 & $\sim 1600$ & -- & 23 & 4.0 & {$[26]$} \\
\hline $\mathrm{Sn}-3.0 \mathrm{Ag}-0.5 \mathrm{Cu}$ & 0.5 & $\sim 1600$ & -- & 23 & 3.9 & [26] \\
\hline \multicolumn{7}{|c|}{ Soldered to $\mathrm{Cu}$ substrate } \\
\hline $\mathrm{Sn}-3.0 \mathrm{Ag}-0.95 \mathrm{Cu}$ & 0.05 & -- & 1.5 & 17.8 & 16.7 & {$[25]$} \\
\hline $\mathrm{Sn}-3.0 \mathrm{Ag}-0.95 \mathrm{Cu}$ & 0.1 & -- & 1.5 & 17.8 & 20.4 & {$[25]$} \\
\hline $\mathrm{Sn}-3.0 \mathrm{Ag}-0.95 \mathrm{Cu}$ & 0.15 & -- & 1.5 & 17.8 & 23.1 & {$[25]$} \\
\hline $\mathrm{Sn}-3.0 \mathrm{Ag}-0.95 \mathrm{Cu}$ & 0.1 & -- & 0.17 & 15.4 & 13.4 & [25] \\
\hline $\mathrm{Sn}-3.0 \mathrm{Ag}-0.95 \mathrm{Cu}$ & 0.15 & -- & 0.17 & 15.4 & 11.1 & {$[25]$} \\
\hline $\mathrm{Sn}-3.5 \mathrm{Ag}-0.95 \mathrm{Cu}$ & 0.1 & 1579 & 0.17 & 7.5 & 13.6 & {$[28]$} \\
\hline $\mathrm{Sn}-3.5 \mathrm{Ag}-0.95 \mathrm{Cu}$ & 0.15 & 1579 & 0.17 & 7.5 & 13 & [28] \\
\hline $\mathrm{Sn}-3.5 \mathrm{Ag}-0.95 \mathrm{Cu}$ & 0.25 & 1579 & 0.17 & 7.5 & 13.2 & [28] \\
\hline
\end{tabular}

Table 2 Compositions of SAC305, SAC305-0.05Co, and SAC305-0.4Co measured by XRF spectroscopy

\begin{tabular}{lllllllllll}
\hline Alloys & $\begin{array}{l}\mathrm{Ag} \\
{[\mathrm{wt} \%]}\end{array}$ & $\begin{array}{l}\mathrm{Cu} \\
{[\mathrm{wt} \%]}\end{array}$ & $\begin{array}{l}\mathrm{Co} \\
{[\mathrm{wt} \%]}\end{array}$ & $\begin{array}{l}\mathrm{Pb} \\
{[\mathrm{wt} \%]}\end{array}$ & $\begin{array}{l}\mathrm{Sb} \\
{[\mathrm{wt} \%]}\end{array}$ & $\begin{array}{l}\mathrm{Bi} \\
{[\mathrm{wt} \%]}\end{array}$ & $\begin{array}{l}\mathrm{Ni} \\
{[\mathrm{wt} \%]}\end{array}$ & $\begin{array}{l}\mathrm{Fe} \\
{[\mathrm{wt} \%]}\end{array}$ & $\begin{array}{l}\mathrm{Zn} \\
{[\mathrm{wt} \%]}\end{array}$ & $\begin{array}{l}\mathrm{Sn} \\
{[\mathrm{wt} \%]}\end{array}$ \\
\hline SAC305 & 2.920 & 0.586 & 0.002 & 0.024 & 0.018 & 0.013 & 0.006 & 0.004 & $<0.001$ & $\mathrm{Bal}$. \\
SAC305-0.05Co & 2.940 & 0.588 & 0.049 & 0.024 & 0.018 & 0.013 & 0.008 & 0.005 & $<0.001$ & $\mathrm{Bal}$. \\
SAC305-0.4Co & 2.810 & 0.539 & 0.378 & 0.023 & 0.020 & 0.010 & 0.007 & 0.004 & $<0.001$ & Bal. \\
\hline
\end{tabular}

Table 3 SEM-EDX results on $\mathrm{Cu}_{6} \mathrm{Sn}_{5}$ and $\alpha \mathrm{CoSn}{ }_{3}$ from the settled layer in Figure 1. Average values with standard deviations in brackets are given

\begin{tabular}{ccccrc}
\hline Phase & Tested number & $\mathrm{Fe}[\mathrm{at} \%]$ & \multicolumn{1}{c}{$\mathrm{Co}[\mathrm{at} \%]$} & \multicolumn{1}{c}{$\mathrm{Cu}[\mathrm{at} \%]$} & $\mathrm{Sn} \mathrm{[at \% ]}$ \\
\hline $\mathrm{Cu}_{6} \mathrm{Sn}_{5}$ & 35 & $0.63(0.24)$ & $8.94(0.33)$ & $47.14(0.88)$ & $43.29(0.85)$ \\
$\alpha \mathrm{CoSn}_{3}$ & 33 & $1.37(0.20)$ & $16.02(0.63)$ & $6.90(0.88)$ & $75.71(0.69)$ \\
\hline
\end{tabular}


Table 4 The measured characteristic nucleation temperatures and grain size for SAC305 and SAC305$0.05 \mathrm{Co}$ ( 4 samples for each). Mean values with standard deviations in brackets are given

\begin{tabular}{cccccc}
\hline & $\begin{array}{c}\text { Cooling } \\
\text { rate }(\mathrm{K} / \mathrm{s})\end{array}$ & $\mathrm{T}_{\min }(\mathrm{K})$ & $\mathrm{T}_{\max }(\mathrm{K})$ & $\Delta \mathrm{T}(\mathrm{K})$ & $\begin{array}{c}\text { Grain } \\
\operatorname{size}(\mu \mathrm{m})\end{array}$ \\
\hline SAC305 & $1.0(0.2)$ & $203.1(0.4)$ & $217.6(0.1)$ & $14.3(0.3)$ & $3878(148)$ \\
SAC305-0.05Co & $1.1(0.1)$ & $218.3(0.5)$ & $218.5(0.5)$ & $0.2(0.1)$ & $1175(65)$ \\
\hline
\end{tabular}

Table 5 lattice mismatch between (100) $\beta S n$ and parallel planes in $\mathrm{XSn}_{4}$ and $\alpha \mathrm{CoSn}_{3}[34]$

\begin{tabular}{lccccc}
\hline & $(100)$ & $(008)$ & $(008)$ & $(008)$ & $(600)$ \\
& $\beta S n$ & NiSn4 & PdSn4 & PtSn4 & $\alpha \operatorname{CoSn}_{3}$ \\
\hline Atomic density (atoms nm $\left.{ }^{-2}\right)$ & 10.78 & 9.77 & 9.72 & 9.73 & 10.18 \\
Row angle & $149.5^{\circ}$ & $145.6^{\circ}$ & $145.0^{\circ}$ & $145.6^{\circ}$ & $149.7^{\circ}$ \\
Effective spacing mismatch along zig-zag rows (\%) & -- & 9.6 & 10 & 10 & 7.5 \\
Spacing mismatch between zig-zag rows (\%) & -- & 0.3 & 0.3 & 0.6 & 1.4 \\
Spacing mismatch between interfacial planes (\%) & -- & 3.0 & 2.5 & 2.6 & 3.6 \\
\hline
\end{tabular}

Table 6 SEM-EDX measured compositions of $\mathrm{Cu}_{6} \mathrm{Sn}_{5}$ in $\mathrm{SAC} 305-0.05 \mathrm{Co} / \mathrm{Cu}$ solder joints. Average values with standard deviations in brackets are given

\begin{tabular}{ccccc}
\hline & $\begin{array}{c}\text { Tested } \\
\text { number/points }\end{array}$ & $\mathrm{Co}[\mathrm{at} \%]$ & $\mathrm{Cu}[\mathrm{at} \%]$ & $\mathrm{Sn}[\mathrm{at} \%]$ \\
\hline Primary $\mathrm{Cu}_{6} \mathrm{Sn}_{5}$ & 35 & $5.32(0.89)$ & $41.95(3.70)$ & $52.73(3.88)$ \\
Interfacial $\mathrm{Cu}_{6} \mathrm{Sn}_{5}$ & 37 & $1.70(0.37)$ & $48.70(1.65)$ & $49.60(1.65)$ \\
\hline
\end{tabular}



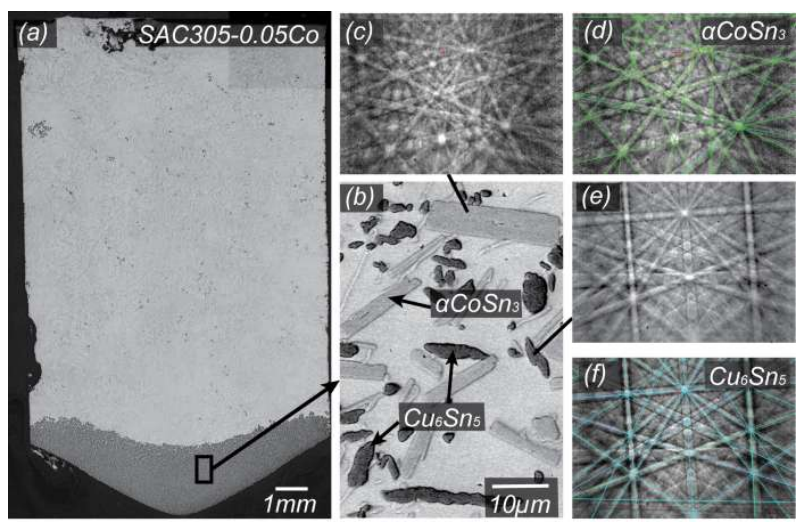

Figure 1 Bottom section of the SAC305-0.05Co isothermal holding sample: (a) optical metallograph, (b) backscattered electron image, (c) EBSD pattern of a typical $\alpha \mathrm{CoSn}_{3}$ phase, (d) EBSD pattern indexed as $\alpha \operatorname{CoSn}_{3}$, (e) EBSD pattern of a typical $\mathrm{Cu}_{6} \mathrm{Sn}_{5}$ phase, (f) EBSD pattern indexed as $\eta \mathrm{Cu}_{6} \mathrm{Sn}_{5}$ 

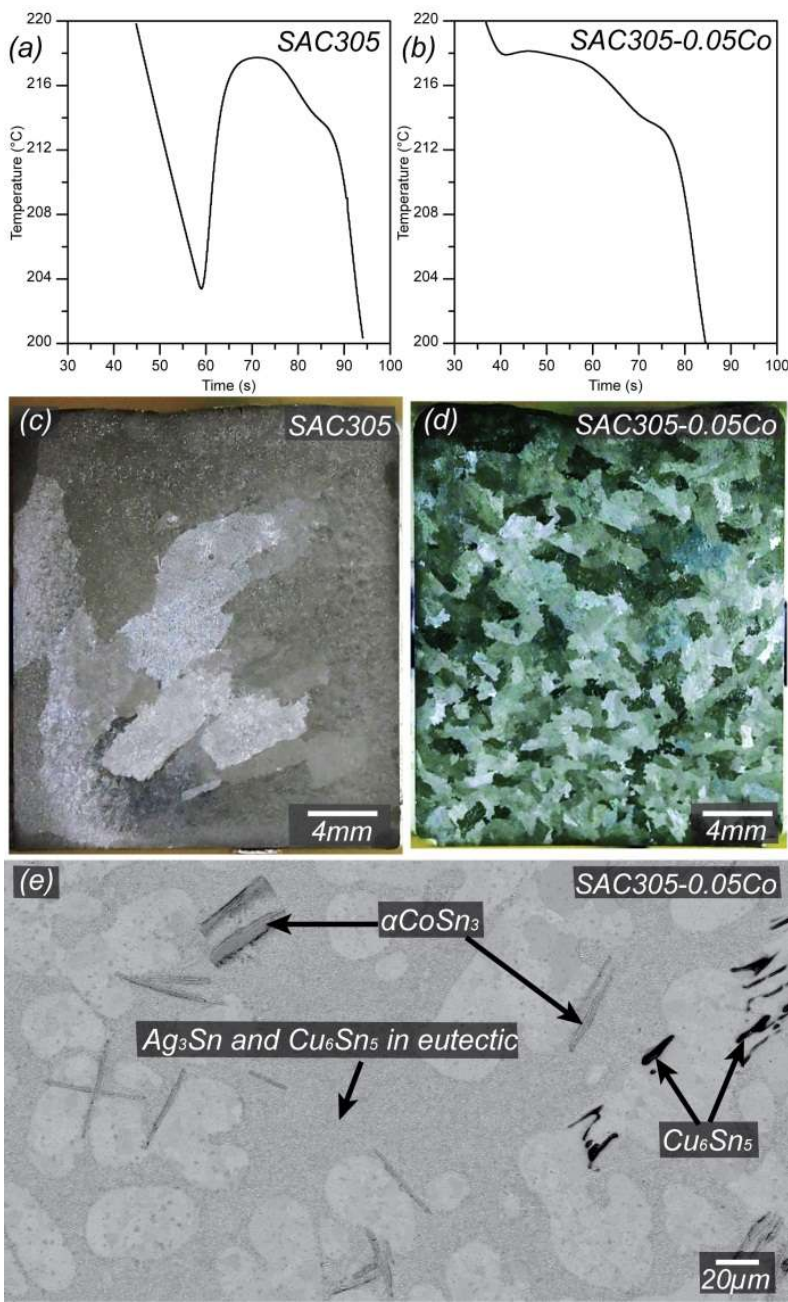

Figure 2 Typical cooling curves and etched microstructures of SAC305((a) and (c)) and SAC305-0.05Co((b) and (d)) 60g samples, (e) a backscattered electron image showing the microstructure and phases in a typical SAC3050.05Co sample. 


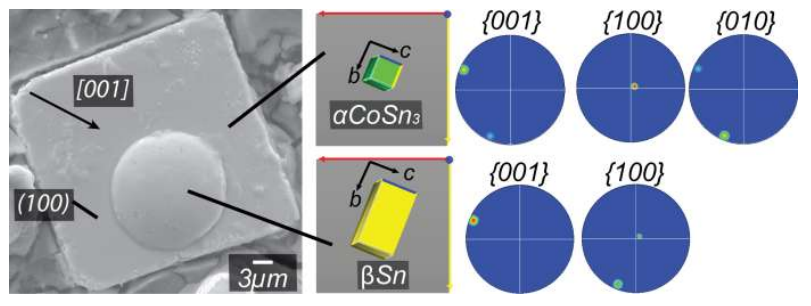

Figure 3 A typical Sn droplet solidified on the (100) facet of an $\alpha \mathrm{CoSn}_{3}$ single crystal with corresponding unit cell orientations and pole figures 
(a)

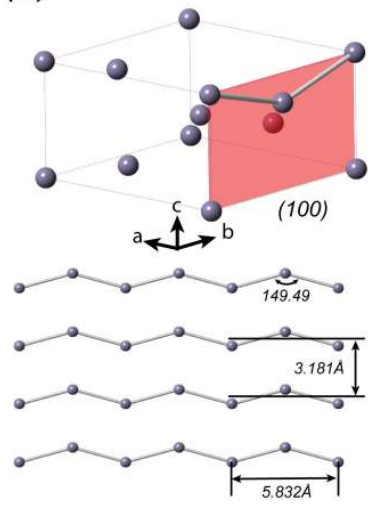

(b) ${ }^{a \cos n s}$

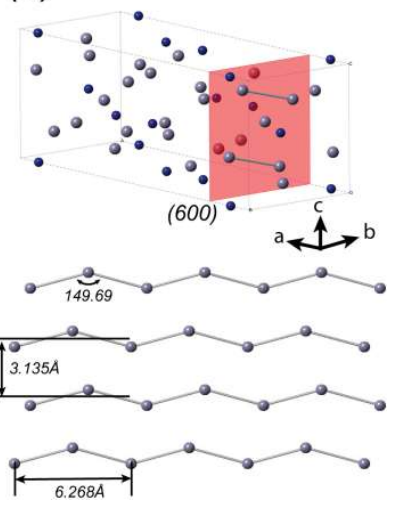

Figure 4 Interfacial planes and lattice match based on Figure 3: (a) (100) plane in $\beta S n$ and (b) (600) plane in $\alpha \mathrm{CoSn}_{3}$ 


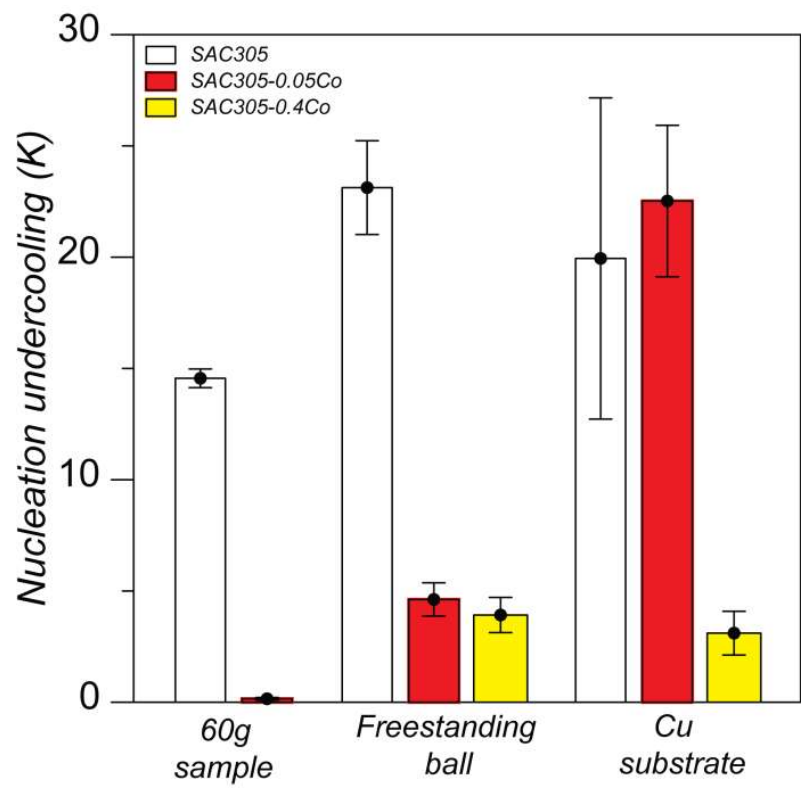

Figure 5 Nucleation undercooling for $\beta S n$ in $60 \mathrm{~g}$ samples, $550 \mu \mathrm{m}$ freestanding solder balls and solder joints. Mean values and standard deviations are shown based on at least 20 measurements for each solder/substrate combination. 

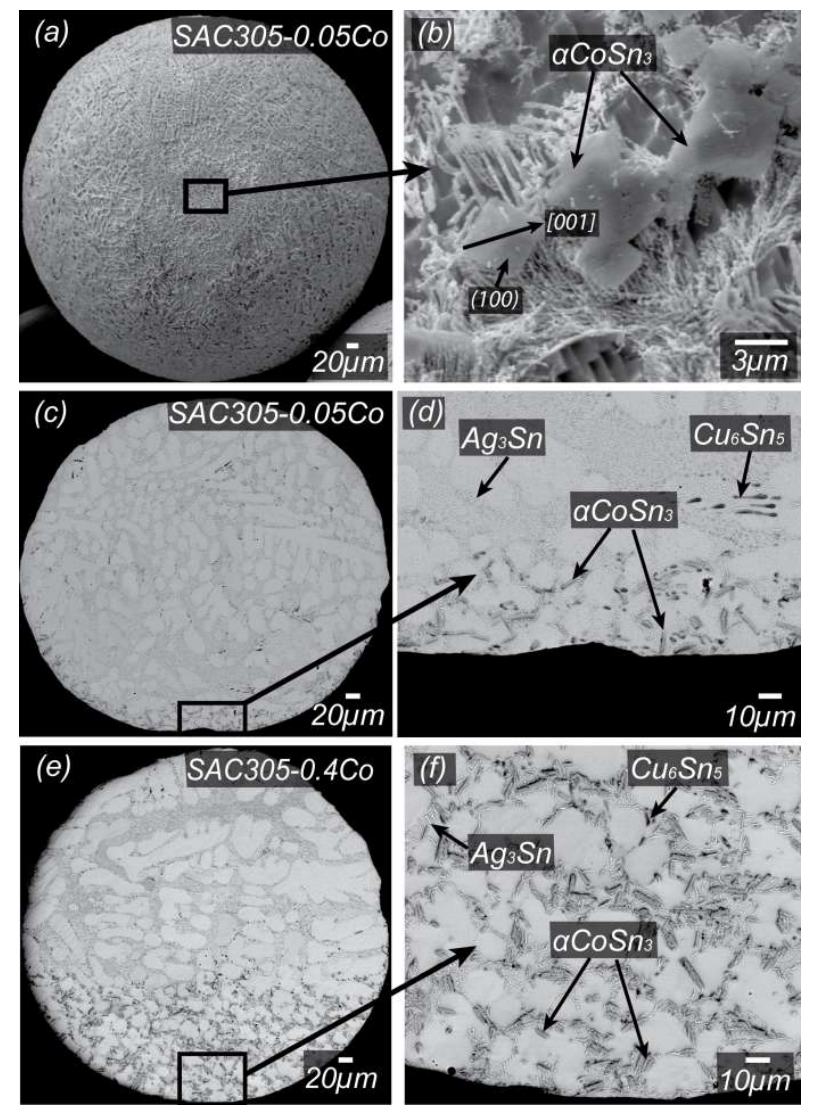

Figure 6 Typical $\alpha \operatorname{CoSn} 3$ particles in DSC reflowed freestanding balls. (a)-(b) SAC305-0.05Co after selective dissolution of $\beta S$ n. (c)-(d) SAC305-0.05Co cross-section. (e)-(f) SAC305-0.4Co cross-section. Samples are oriented with gravity downwards in (c)-(f) 

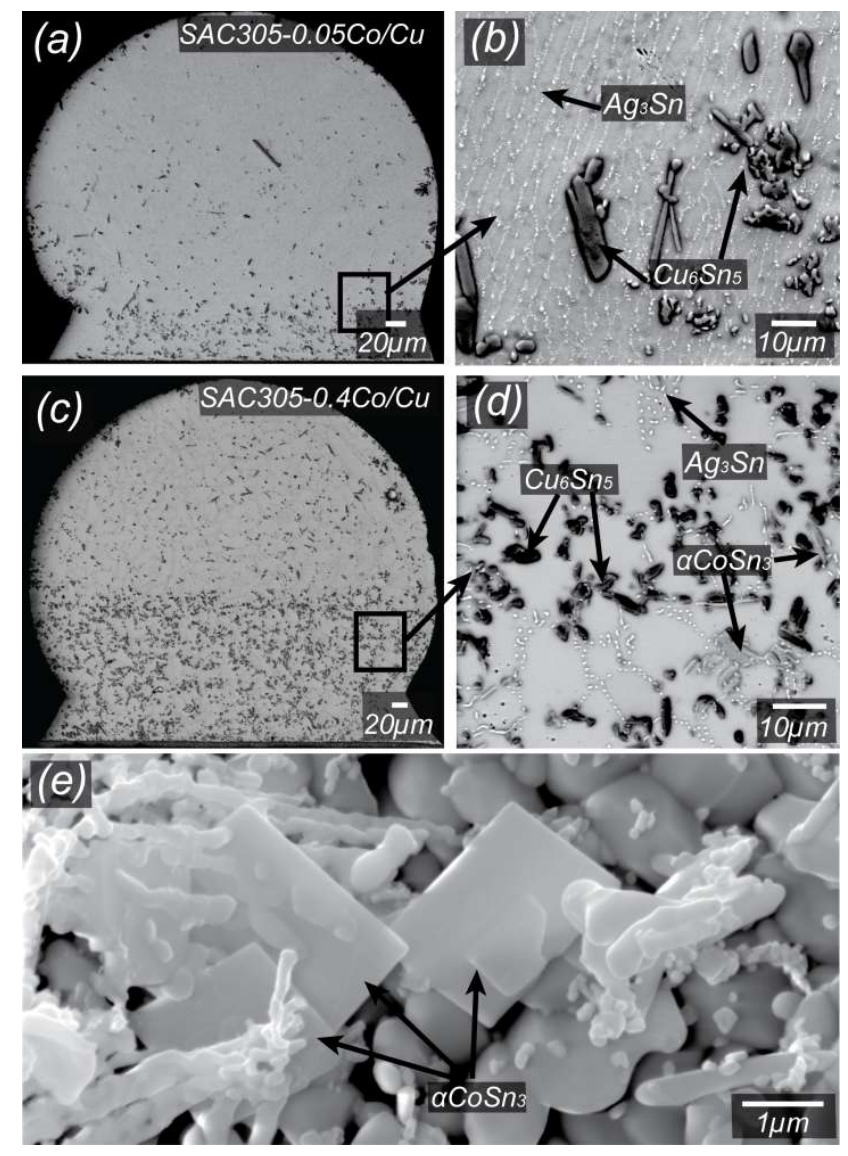

Figure 7 Microstructures of typical DSC reflowed SAC305-0.05Co/Cu ((a) and (b)) and SAC305$0.4 \mathrm{Co} / \mathrm{Cu}$ joints ((c) and (d)), (e) shows CoSn3 particles in a typical SAC305-0.4Co/Cu joint 


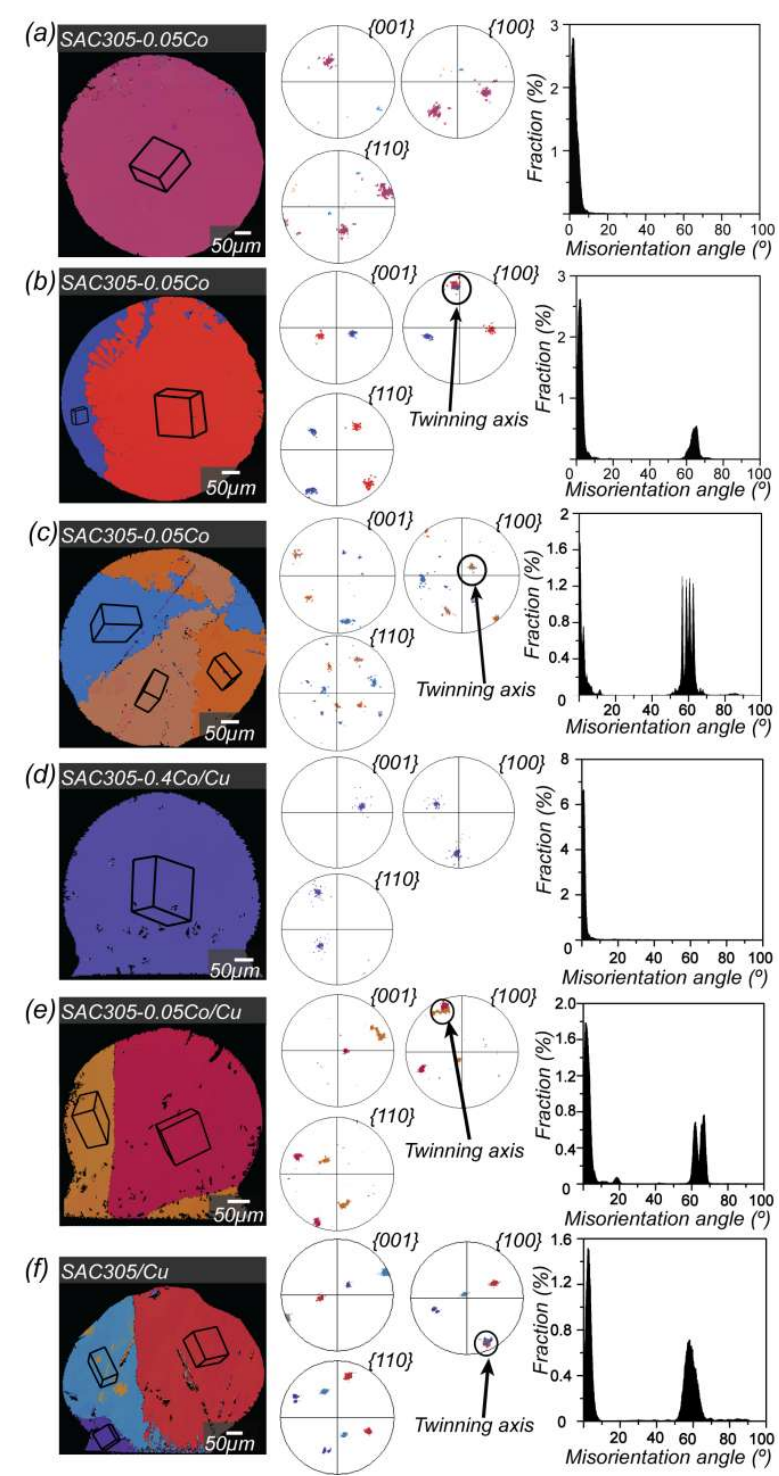

Figure 8 The three types of $\beta S n$ grain structure observed in balls and joints cooled in the DSC at $0.33 \mathrm{~K} / \mathrm{s}$. (a)-(f) from left to right: EBSD orientation maps, pole figures with the same colour scale as the orientation maps, and misorientation angle distributions. (a) and (d) single grain. (b) and (e) 2 grains related by $\sim 60^{\circ}$ twinning around a single [100] or [010]. (c) and (f) 3 grains related by $\sim 60^{\circ}$ twinning around a single [100] or [010] axis (including beachball structures) 


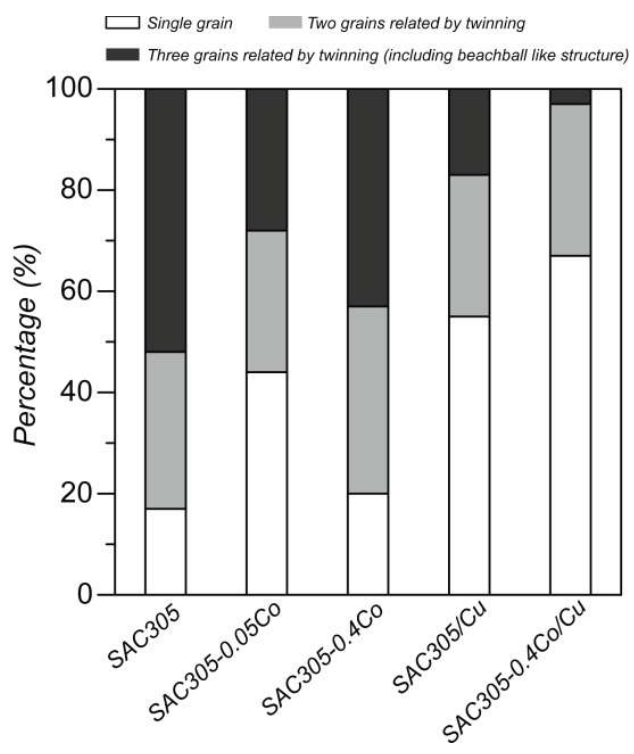

Figure 9 The frequency of occurrence of the three structures in freestanding balls and joints cooled in the DSC at $0.33 \mathrm{~K} / \mathrm{s}$, based on at least 30 samples for each composition. Note that all structures arise from a single nucleation event 

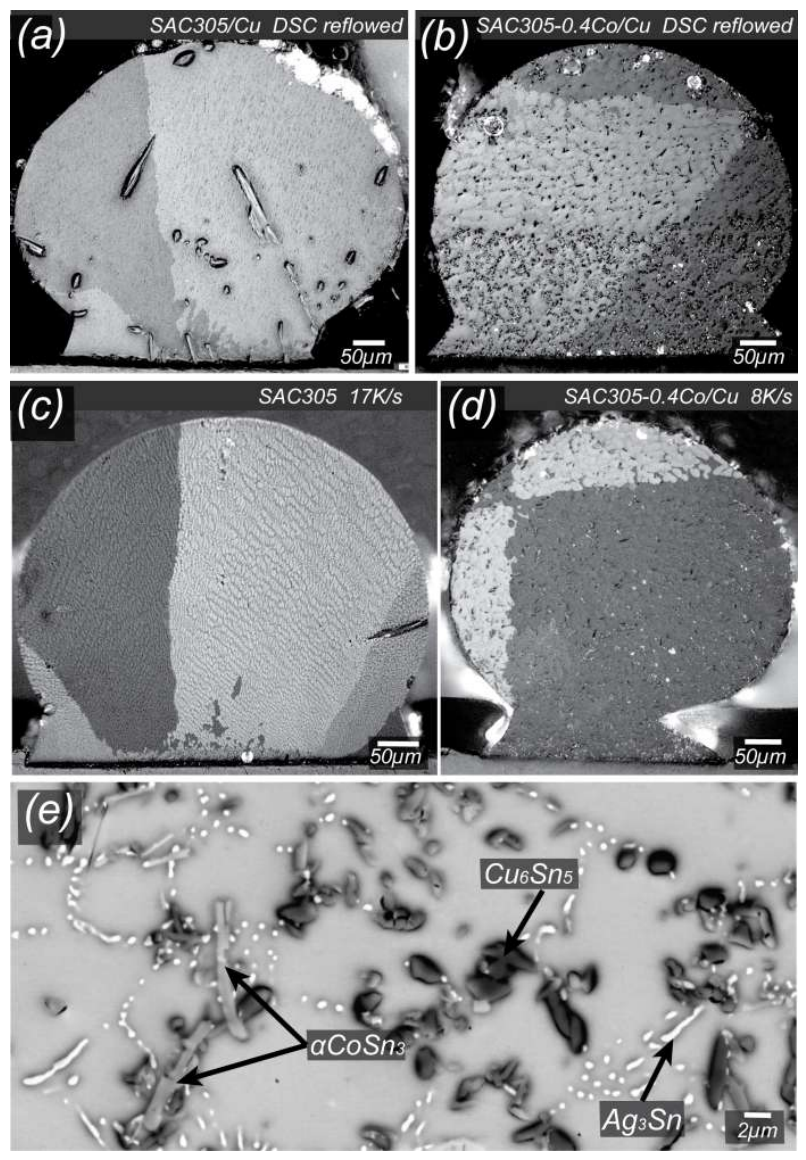

Figure 10 Typical joints in which the nucleation location can be determined in the sectioning plane from the intersection of the twinned dendrites. $\beta S n$ grew from the $\mathrm{Cu}_{6} \mathrm{Sn}_{5}$ interfacial layer in (a) DSC reflowed SAC305/Cu and (c) fast cooled SAC305/Cu (at $17 \mathrm{~K} / \mathrm{s}$ ). $\beta$ Sn nucleated in the solder bulk in (b) DSC reflowed SAC305-0.4Co/Cu and in (d) fast cooled SAC305-0.4Co/Cu (at $~ 8 \mathrm{~K} / \mathrm{s}$ ). (e) SEM image showing that there are $\alpha \mathrm{CoSn}_{3}$ particles in the nucleation location of solder bulk in SAC305$0.4 \mathrm{Co} / \mathrm{Cu}$ in (b). Note that it is unlikely that the nucleation location is exactly in the sectioning plane in (a)-(d). 


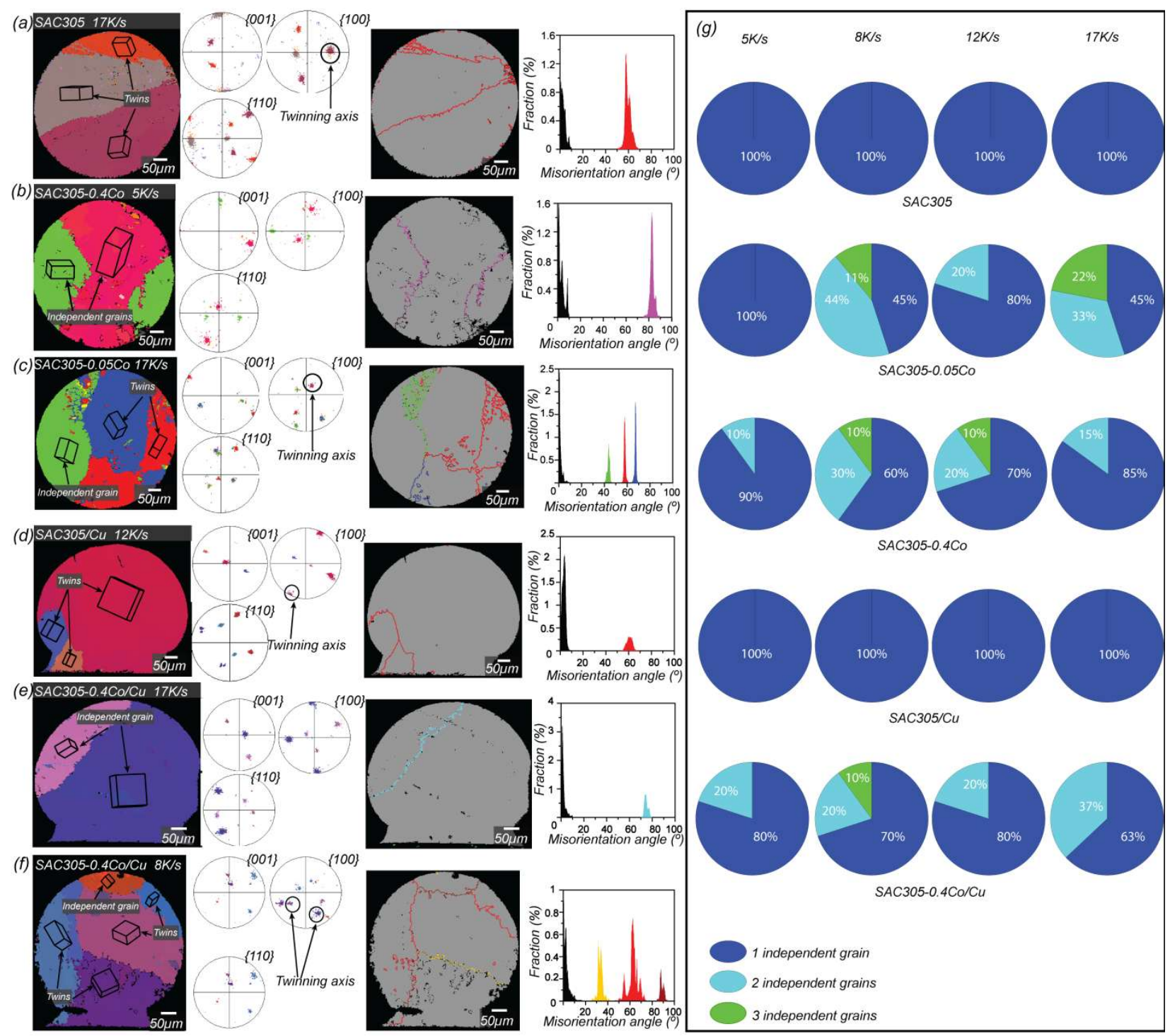

Figure $11 \mathrm{~A}$ representative range of $\beta S n$ grain structures in balls and joints cooled at 5-17K/s. (a)-(f) From left to right: EBSD orientation maps, pole figures with the same colour scales as the orientation maps, grains boundary (GB) maps highlighting the high angle GBs, and misorientation angle distributions with the same colour scale as the GB maps. (a) and (d) contain 3 orientations but only 1 independent (not related by twinning or CSL) grain; (b) and (e) contain 2 orientations and 2 independent grains; (c) contains 3 orientations and 2 independent grains; (f) contains 5 orientations and 3 independent grains. (g) Pie charts summarizing the frequency of the number of independent grains in freestanding balls and joints at four cooling rates. 

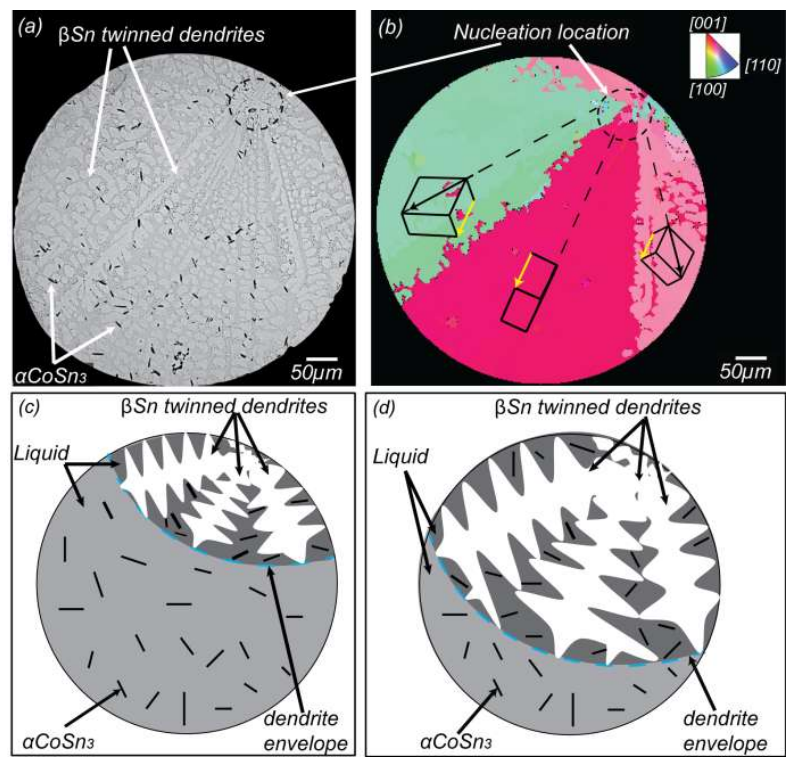

Figure 12: Nucleation and growth of $\beta S n$ in solder balls containing $\alpha \operatorname{CoSn}_{3}$, using a freestanding SAC305-0.05Co beachball cooled at $5 \mathrm{~K} / \mathrm{s}$ as an example. (a) Optical micrograph showing the phases and dendrite growth directions; (b) EBSD IPFX map with wireframe unit cells. Black vectors and dashed lines show the $<110\rangle$ dendrite growth directions which 'point back' to the nucleation location. Yellow vectors show the common [100] or [010] twin axis. Note that it is unlikely that the nucleation location is exactly in the sectioning plane and that none of the $\langle 110\rangle$ directions are in-plane. (c) and (d) 2D schematic representation of two stages early during solidification (before the eutectic reactions begin) based on (a) and (b). 


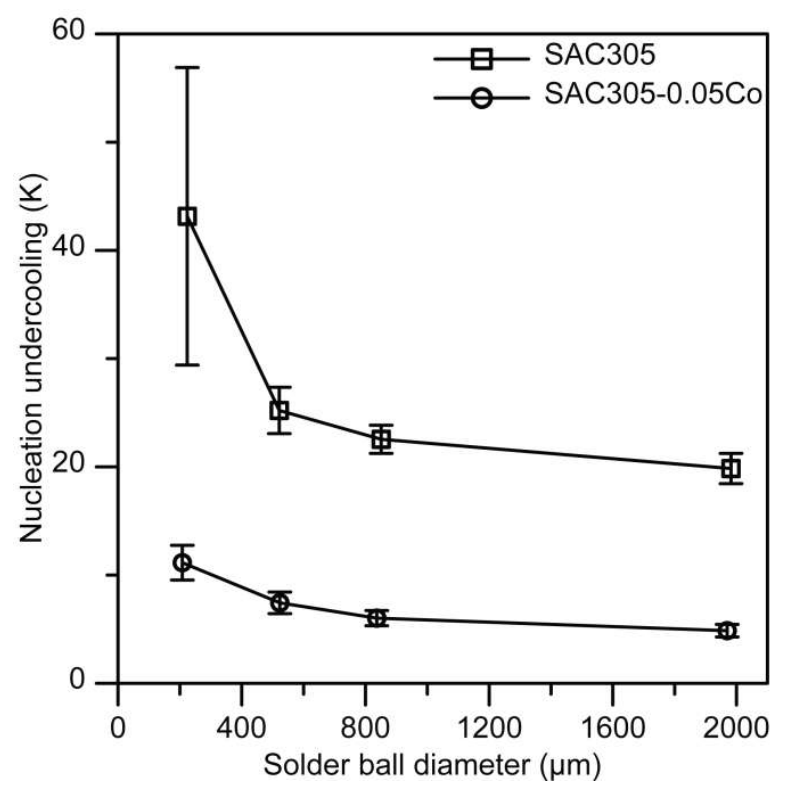

Figure 13 The influence of solder ball size on nucleation undercooling in freestanding balls of SAC 305 and SAC $305-0.05$ Co cooled at $0.83 \mathrm{~K} / \mathrm{s}$ in a DSC. Error bars are standard deviations from 12 measurements. 